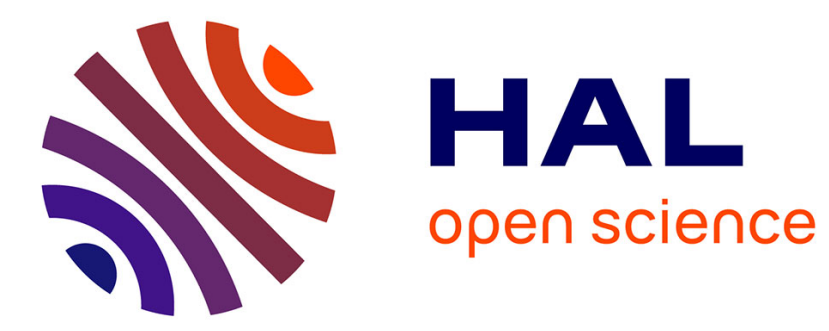

\title{
Mass \& energy balances coupling in chemical reactors for a better understanding of thermal safety
}

Sébastien Leveneur, Lamiae Vernières-Hassimi, Tapio Salmi

\section{To cite this version:}

Sébastien Leveneur, Lamiae Vernières-Hassimi, Tapio Salmi. Mass \& energy balances coupling in chemical reactors for a better understanding of thermal safety. Education for Chemical Engineers, 2016, 16, pp.17-28. 10.1016/j.ece.2016.06.002 . hal-02435639

\section{HAL Id: hal-02435639}

https://hal-normandie-univ.archives-ouvertes.fr/hal-02435639

Submitted on 21 Dec 2021

HAL is a multi-disciplinary open access archive for the deposit and dissemination of scientific research documents, whether they are published or not. The documents may come from teaching and research institutions in France or abroad, or from public or private research centers.
L'archive ouverte pluridisciplinaire HAL, est destinée au dépôt et à la diffusion de documents scientifiques de niveau recherche, publiés ou non, émanant des établissements d'enseignement et de recherche français ou étrangers, des laboratoires publics ou privés. 


\section{Mass \& energy balances coupling in chemical reactors for a better understanding of thermal safety}

Sébastien LEVENEUR ${ }^{1,2}$, Lamiae VERNIERES-HASSIMI ${ }^{2}$,Tapio SALMI ${ }^{1}$

${ }^{1}$ Laboratory of Industrial Chemistry and Reaction Engineering, Johan Gadolin Process

Chemistry Centre, Åbo Akademi University, Biskopsgatan 8, FI-20500 Åbo/Turku, Finland. E-mail: sebastien.leveneur@insa-rouen.fr

2 Normandie Université LSPC-Laboratoire de Sécurité des Procédés Chimiques, EA4704, INSA/Université Rouen, 685 Avenue de l'université, BP 08, 76801 Saint-Etienne-duRouvray, France; fax: +33 232956652 . 


\section{ABSTRACT}

Process safety is an important topic in the curriculum vitae of a chemical engineer. It can be a difficult course for the students and professors, because it is a frontier course between chemical engineering and safety. How to introduce this course? We think that this course should be introduced during the chemical reaction engineering, and more particularly during the mass and energy balances lectures. Thus, the students can more easily understand the concept of isoperibolic mode, secondary reactions, heat-flow rate due to chemical reactions, Semenov curves...etc. In this manuscript, we propose a pedagogical method to introduce this concept by using numerical simulation. In the first section, the roots of energy balances for the different reactors is derived. In the second section, mass and energy balances coupling is derived for the different chemical reactors. In the third section, the different thermal modes, i.e., isothermal, isoperibolic and adiabatic are described. Then, a tutorial by using a batch reactor with several exothermic reactions is treated and corrected. At this moment of the course, the instructor can introduce the last section about safety criteria by using the zero-order approximation. The rigorous mass and energy balances coupling should be introduced

to the students before the current approximation made by the safety community, i.e., zero order, in process safety. 


\section{KEYWORDS}

Chemical Reaction Engineering, Introduction to Thermal Safety of Chemical Processes, Applied Numerical Methods, Mass \& Energy Coupling. 


\section{INTRODUCTION}

The introduction of safety and risk assessment during a chemical engineering curriculum is recommended by different associations (Favre et al. (2008), Shallcross (2013), Perrin (2008), Dee et al. (2015) and Spicer et al. (2012)). Process safety for chemical engineers can be a difficult course for the students and for the professors, because it includes several concepts from thermodynamics, reaction kinetics, chemical reaction engineering, process design, accident scenario development and even sociology. A chemical engineer should appreciate the risk of thermal runaway which can cause a pressure elevation and an explosion of the vessel. The evolution of heat-flow rate due to chemical reactions should be known, thus kinetics and thermodynamics of the chemical system should be determined. When the behavior of the heat-flow rate due to chemical reactions is known, the chemical engineers could design a system to remove the excess of heat to diminish the risk of thermal runaway. For that reason, different Chemical Reaction Engineering (CRE) books have integrated one chapter on process safety or on thermal stability of reactor (Coker (2001), Fogler (2016), Rawlings and Ekerdt (2013), Villermaux (1999)). We should also mention the book of Francis Stoessel on thermal process safety assessment (Stoessel (2008)). By segregating this lecture of thermal safety from CRE, students could use some formulae to calculate safety criteria based on zero-order reaction.

We are also convinced that this course can be introduced as a chapter in chemical reaction engineering $(\mathrm{CRE})$ courses. More particularly, during the lectures on mass and energy balances. During our lectures of CRE and reactor stability at Åbo Akademi University or at INSA Rouen, we have noticed that we should spend more time to illustrate properly the strong coupling of mass and energy balances. Thus, students learn how to determine the different heat-flow rates in a chemical reactor which 
illustrates the dynamic of the system. The thermal safety criteria are often introduced with a static approach: by assuming full accumulation, adiabatic conditions, single reaction and zero-order reaction. The main drawback with that approach is those students do not study properly the determination of heat-flow rate under different thermal modes in presence of multiple reactions. This static approach, based on the worst case scenario, could lead to some confusion for the future chemical engineers. The different concepts of time to maximum rate under adiabatic conditions $T_{M} R_{a d}$, or adiabatic temperature rise $\Delta \mathrm{T}_{\mathrm{ad}}$ during process safety lectures can be abstract to understand and handle (Stoessel (2008)). Based on our experience, we have developed a pedagogical strategy including numerical simulation to ease the understanding of such concept during a CRE course for undergraduate and master students (Antunes et al. (2011), Lindfors (1971) and Taipa et al. (2015)). The use of simulation is an efficient pedagogical tool to understand the dynamic of a chemical reaction system (Coker (2001), Finlayson (2006), Fogler (1999), Law (2013), Rawlings and Ekerdt (2013), Salmi et al. (2010)). However, the instructors should spend time to explain correctly the program to the students. Furthermore, due to the introduction of simplification, the results of the simulation should be viewed with caution, essentially during the stage of design (Levenspiel (1999)).

The main objective of this manuscript is to propose a dynamic view of safety criteria by using simulation. Figure 1 illustrates the pedagogical approach. It is not a course on process safety, which should take place after this course. Some articles have modeled some accidents or scenarii, but these case studies are for master or post-graduate students (Eizenberg et al. (2006), Willey et al. (2011) and Dixon et al. (2015)). We did not simulate the evolution of the pressure in the reactors head space during this course. During the lecture, we mention that pressure increase can be due to the evaporation of the reaction mixture and decomposition reactions producing non- 
condensable products. We think that this part can be seen during the safety course and particularly during practices. As illustrated by Willey et al. (2011), the example of an industrial accident can be used by using VSP 2 technology.

\section{HERE Fig. 1.}

The course (around 20 hours) includes the following main topics:

- Mass and energy balances (3 hours)

- Different thermal mode (3 hours)

- Tutorials based on numerical simulation (5 hours)

- Thermal safety assessment (4 hours)

- Project (5 hours)

The first six hours of the course are dedicated to lectures of mass \& energy balances in chemical reactors and the different thermal modes. This introduction is fundamental for students, because they can understand why there is a strong mass $\&$ energy balances coupling and the importance of the thermal mode. The personal student work is between 3-6 hours.

The next part of the course ( 5 hours) is dedicated to practice to simulation by using Matlab. The instructors should explain the skeleton of the Matlab code and the exercises. The instructor can individually adapt the proposed exercises to the students. The students must solve out the different exercises by using Matlab (2 or 1 student per computer). This part of the course can be the most demanding for the students and the instructors. It is essential that the students feel familiar with the code to understand the effect of initial reaction and jacket temperature, initial concentrations, thermal parameters and thermal mode on the evolution of heat-flow rate, concentration 
distribution and temperature with reaction time. The personal student work is important for this part. Depending on student computing capacity, the personal can be estimated to 5-10 hours.

The lecture concerning the thermal safety assessment is a lecture, and the personal student work is typically 4 hours.

The project should be done by the students. Several configurations have been tested: personal, pair or group project; liberty for the student to choose their partners or the instructor defines a system to make the groups. Based on our experience, the pedagogical results are better when students work by pair and when they choose their

partners. The computer room is reserved for the students one time per week. They have 3 weeks to finish that project.

Due to the space limitation of the journal, we have decided to put as supplementary information different elements of the course. For the sake of simplicity, only a batch reactor is described in this manuscript.

\section{REMIND OF MASS BALANCE AND KINETICS IN A REACTOR}

Energy balance for chemical reactors is strongly linked to mass balance. Hence, it is important to refresh the fundamentals of mass balances for chemical reactors. Indeed, this course is after the first course of CRE, where the different ideal reactors were described. The instructor should insist on the fact that mass and energy balance are done on a delimited zone (liquid reaction, gas phase.). For example, in case of liquid mono-phase reaction systems, we should pay attention to the fact that the mass balance is derived for the liquid phase. It is quite obvious to state this, but in case of temperature increase, such as a thermal runaway, evaporation and decomposition 
reactions producing non-condensable products could occur, and make the mass balance more complex.

For undergraduate or master students, it is important to treat liquid reaction systems under high pressure (inert gas) to neglect evaporation phenomenon. The instructor should show some examples neglecting secondary reactions, i.e., reactions with high activation energy producing non-condensable products. The reason of this simplification is the complexity to describe the pressure evolution in the gas-phase during decomposition reactions occurring in the liquid-phase. The resolution of such system (liquid-phase reactions producing non-condensable products) should be reserved for advanced CRE courses. However, this simplification should really be emphasized during the lectures. Indeed, the thermal risk comes from the thermal runaway, which could lead to an overpressure due to secondary reactions and liquid vapor pressure. Fig. 2 presents the mass balance expressions for the different chemical reactors. An other important reminder from the first course of CRE is the difference between steady-state and unsteady-state regime.

\section{HERE Fig. 2.}

The mass balance for a compound in an ideal batch reactor is usually written as

$\frac{\mathrm{dC}_{\mathrm{j}}}{\mathrm{dt}}=\sum_{i=1}^{n_{r}} v_{i j} \cdot \mathrm{R}_{\mathrm{i}}$ or $\frac{\mathrm{dn}_{\mathrm{j}}}{\mathrm{dt}}=V_{R} \cdot \sum_{i=1}^{n_{r}} v_{i j} \cdot \mathrm{R}_{\mathrm{i}}$

where, $\mathrm{j}$ refers the compound, $v_{\mathrm{ij}}$ is the stoichiometry coefficient of compound $\mathrm{j}$ for reaction $i, R_{i}$ is the reaction rate and $V_{R}$ is the reaction volume. 


\section{MASS AND ENERGY BALANCE COUPLING IN A CHEMICAL REACTOR}

This part might be the most difficult to absorb by the students, and it is worth to come back to the traditional blackboard to explain each terms in the energy balance. The roots of energy balance in a chemical reactor can be found in supplementary information (S1) inspired from the book of James B. Rawlings and John G. Ekerdt (2013).

By neglecting enthalpy changes due to phase transfer, energy balance for any chemical reactors is given by

$\left(\mathrm{V}_{\mathrm{R}} \cdot \rho_{\mathrm{R}} \cdot \hat{\mathrm{C}}_{\mathrm{P}_{\mathrm{R}}}+\mathrm{m}_{\text {insert }} \cdot \hat{\mathrm{C}}_{\mathrm{P}_{\mathrm{inset}}}\right) \frac{\mathrm{dT}_{\mathrm{R}}}{\mathrm{dt}}-\alpha \cdot \mathrm{T}_{\mathrm{R}} \cdot \mathrm{V}_{\mathrm{R}} \cdot \frac{\mathrm{dP}_{\mathrm{R}}}{\mathrm{dt}}+\sum_{\mathrm{j}} \overline{\mathrm{H}}_{\mathrm{j}} \frac{\mathrm{dn}_{\mathrm{j}}}{\mathrm{dt}}=\dot{\mathrm{H}}_{\mathrm{in}}-\dot{\mathrm{H}}_{\text {out }}+\dot{\mathrm{Q}}_{\text {exch }}+\dot{\mathrm{W}}_{\mathrm{S}}$

where $m_{R}$ and $m_{\text {insert }}$ are the reaction mixture and insert mass, $\hat{C}_{P_{R}}$ and $\hat{C}_{P_{\text {insert }}}$ are constant-pressure specific heat capacities of reaction mixture and insert, respectively, $\mathrm{T}_{\mathrm{R}}$ is the reaction temperature, $\dot{\mathrm{H}}_{\mathrm{in}}$ and $\dot{\mathrm{H}}_{\text {out }}$ are the inflow and outflow enthalpies. The term $\dot{\mathrm{W}}_{\mathrm{S}}$ is shaft power due to the stirring. The term $\dot{\mathrm{Q}}_{\mathrm{exch}}$ (also written $\mathrm{q}_{\text {exch }}$ in the literature) is the exchanged heat-flow rate with the surroundings.

The first term of eq (2) represents the accumulation of the heat-flow rate, the second one represents the variation of heat-flow rate due to the variation of pressure and the third one is the heat-flow rate due to the chemical reactions.

For the accumulation term, the thermal inertia of the inserts can be neglected.

The accumulation term $\frac{\mathrm{dn}_{\mathrm{j}}}{\mathrm{dt}}$ from eq (1) is inserted in eq (2). 
In a batch reactor, the inflow and outflow enthalpies are equal to zero, thus eq (2) becomes

$\left(\mathrm{V}_{\mathrm{R}} \cdot \rho_{\mathrm{R}} \cdot \hat{\mathrm{C}}_{\mathrm{P}_{\mathrm{R}}}+\mathrm{m}_{\text {insert }} \cdot \hat{\mathrm{C}}_{\mathrm{P}_{\text {insert }}}\right) \cdot \frac{\mathrm{dT}_{\mathrm{R}}}{\mathrm{dt}}-\alpha \cdot \mathrm{T}_{\mathrm{R}} \cdot \mathrm{V}_{\mathrm{R}} \cdot \frac{\mathrm{dP}_{\mathrm{R}}}{\mathrm{dt}}+\sum_{\mathrm{j}} \overline{\mathrm{H}}_{\mathrm{j}} \cdot \sum_{i=1}^{\mathrm{n}_{\mathrm{R}}} v_{\mathrm{ij}} \cdot \mathrm{R}_{\mathrm{i}} \cdot \mathrm{V}_{\mathrm{R}}=\dot{\mathrm{Q}}_{\mathrm{exch}}+\dot{\mathrm{W}}_{\mathrm{S}}$

with $\sum_{j} v_{i j} \overline{\mathrm{H}}_{\mathrm{j}}=\sum_{\text {Products }} \Delta \mathrm{H}_{\mathrm{f}, \mathrm{j}}-\sum_{\text {Reactants }} \Delta \mathrm{H}_{\mathrm{f}, \mathrm{j}}=\Delta \mathrm{H}_{\mathrm{Ri}}$

The energy balance for a batch reactor can be defined as

$\left(\mathrm{V}_{\mathrm{R}} \cdot \rho_{\mathrm{R}} \cdot \hat{\mathrm{C}}_{\mathrm{P}}+\mathrm{m}_{\text {insert }} \cdot \hat{\mathrm{C}}_{\mathrm{P}_{\text {insert }}}\right) \cdot \frac{\mathrm{dT}_{\mathrm{R}}}{\mathrm{dt}}-\alpha \cdot \mathrm{T}_{\mathrm{R}} \cdot \mathrm{V}_{\mathrm{R}} \cdot \frac{\mathrm{dP}_{\mathrm{R}}}{\mathrm{dt}}+\sum_{i=1}^{\mathrm{n}_{\mathrm{R}}} \Delta \mathrm{H}_{\mathrm{Ri}} \cdot \mathrm{R}_{\mathrm{i}} \cdot \mathrm{V}_{\mathrm{R}}=\dot{\mathrm{Q}}_{\text {exch }}+\dot{\mathrm{W}}_{\mathrm{S}}$

The instructor should insist on the fact that stoichiometric coefficients disappeared in eq (4) and the reaction rates are used and not the generation rates. Some simplification regarding the pressure can be introduced (S2). It is important to emphasize on the fact that temperature is a global signal and we assume no temperature gradients for an ideal reactor.

The instructor could present the different ways to determine the thermal parameters. For example, heat capacity can be determined by using differential scanning calorimeter (Stoessel (2008)) and the global heat transfer coefficient can be measured by using a calibration probe providing an electrical power to the mixture (Leveneur et al. (2012)). The energy balances for the other reactors are described in Fig. 3.

\section{HERE Fig. 3.}

The heat-flow rate due to the chemical reactions is given by the relation:

$$
\dot{\mathrm{Q}}_{\mathrm{rx}} \text { or } \mathrm{q}_{\mathrm{rx}}=\sum_{i=1}^{\mathrm{n}_{\mathrm{R}}} \mathrm{R}_{\mathrm{i}} \cdot \Delta \mathrm{H}_{\mathrm{Ri}} \cdot \mathrm{V}_{\mathrm{R}}
$$


Eq (5) is fundamental to understand the concept of probability and severity, which is the definition of risk. The reaction enthalpy represents the severity of a chemical reaction. The instructor should insist on the fact that the product reaction kinetics times reaction enthalpy represent the thermal risk. The instructor can give the example of hydrogen peroxide decomposition in acidic copper sulfate solutions (Mlasi et al. (2015)). Mlasi et al. (2015) have shown that in absence of copper sulfate, i.e., catalyst, the adiabatic temperature rise is lower than $1^{\circ} \mathrm{C}$.

\section{CONSIDERATION OF DIFFERENT THERMAL MODE}

From a safety viewpoint, it is essential to present the three thermal modes. Usually, the students can differentiate the isothermal and adiabatic mode. However, confusion can occur for the isoperibolic conditions. As illustrated in chapter 2 of the book Thermal Safety of Chemical Processes: Risk Assessment and Process Design (Stoessel (2008)), the confusion between isoperibolic and isothermal mode could have detrimental consequences on a process. Numerical applications can help the students to differentiate the three thermal modes.

For the sake of clarity, one should simplify the equation by assuming negligible the shaft work (due to stirring) and by operating under isobaric mode. The difference between isothermal, isoperibolic and adiabatic mode can be explained by using the following simplified equation:

$$
\begin{gathered}
\dot{\mathrm{Q}}_{\mathrm{acc}}=\dot{\mathrm{Q}}_{\mathrm{rx}}+\dot{\mathrm{Q}}_{\mathrm{exch} .} \\
\Leftrightarrow \mathrm{m}_{\mathrm{R}} \cdot \mathrm{C}_{\mathrm{PR}}^{\prime} \cdot \frac{\mathrm{dT}_{\mathrm{R}}}{\mathrm{dt}}=-\sum_{i}^{n_{R}} \mathrm{R}_{\mathrm{i}} \cdot \mathrm{V}_{\mathrm{R}} \cdot \Delta H_{\mathrm{r}}+\mathrm{U} \cdot \mathrm{A} \cdot\left(\mathrm{T}_{\mathrm{j}}-\mathrm{T}_{\mathrm{R}}\right)
\end{gathered}
$$


The instructor should remind to the students that the symbol of heat-flow rate can be written as $\dot{\mathrm{Q}}$ or $\mathrm{q}$. The term $\dot{\mathrm{Q}}_{\text {exch }}$ represents the heat-flow rate exchanged between the reaction mixture and the surroundings, i.e., head space and heat carrier circulating in through the jacket reactor If the heat losses due to liquid evaporation and vapor condensation can be neglected, then the heat-flow rate exchanged can be expressed as $\dot{\mathrm{Q}}_{\mathrm{exch}}=\mathrm{U} \cdot \mathrm{A} \cdot\left(\mathrm{T}_{\mathrm{j}}-\mathrm{T}_{\mathrm{R}}\right)$.

A is the heat-transfer area. $U$ is the global heat-transfer coefficient. This parameter depends on the geometry of the reactor and the nature of the reaction mixture and heat carrier. The instructor could speak about the importance of these two parameters for the scale-up and for the safety issues. He/she can also introduce the concept of Wilson plot to determine evolution of the parameter U (Lavanchy (2005)). The instructor should mention that the global heat-transfer coefficient depends also on the stirring speed.

Under isothermal conditions, the accumulation term of eq (6) is equal to zero. The heatflow rate originating from chemical reactions and exchanged between reaction mixture and surroundings are the same. Consequently, eq (6) becomes:

$$
\mathrm{T}_{\mathrm{j}}=\frac{\sum_{i}^{n_{R}} \mathrm{R}_{\mathrm{i}} \cdot \mathrm{V}_{\mathrm{R}} \cdot \Delta H_{\mathrm{r}}}{\mathrm{U} \cdot \mathrm{A}}+\mathrm{T}_{\mathrm{R}}
$$

Eq (7) is solved with the ordinary differential eq (1).

Under isoperibolic conditions, jacket temperature is maintained constant due to a very rapid circulation of the heat carrier. Then, one should solve the coupled eqs (1) and (6). The instructor should propose an appropriate numerical method. In this case, the ODEs are typically stiff, and a proper solver such as a Rosenbrock method should be used. 
Under adiabatic mode, heat-flow rate exchanged is equal to zero. Thus, eq (6) becomes

$$
\frac{\mathrm{dT}_{\mathrm{R}}}{\mathrm{dt}}=\frac{-\sum_{i}^{n_{R}} \mathrm{R}_{\mathrm{i}} \cdot \mathrm{V}_{\mathrm{R}} \cdot \Delta H_{\mathrm{r}}}{\mathrm{m}_{\mathrm{R}} \cdot \mathrm{C}_{\mathrm{PR}}^{\prime}}
$$

As in the case of isoperibolic mode, the ODEs (1) and (8) should be solved out with the appropriate numerical solver. Fig. 4 illustrates the different thermal modes for a batch reactor based on eq (6)

HERE Fig. 4.

\section{TUTORIAL WITH NUMERICAL APPROACH}

Even if it is not a lecture of numerical methods, the instructor should spend time to explain the different part of the computer code (supporting information S3). The presence of stiff ordinary differential equations should be highlighted. It is important to give a simplified exercise, which neglects the evaporation and the presence of secondary reactions leading to the production of non-condensable gaseous products. Thus, there is no liquid-gas mass transfer to be considered. Some parameters $(\mathrm{Cp}$, density and UA) are assumed to be constant. The instructor should take time to explain the following assumptions:

- Evaporation is neglected and a low vapour pressure reaction mixture was selected, otherwise one should include this in the mass balance and take into account the evolution of the pressure in the head space of the reactor,

- There are no secondary reactions, which would have led to the formation of noncondensable gaseous products interfering with the mass balance of the liquid-phase. 
But also to highlight that in case of thermal runaway, evaporation can act as a safety barrier,

- The instructor should speak about the fact that evaporation is an endothermic phenomenon interfering with the energy balance of the liquid phase,

- The heat exchange capacity of the reaction mixture can be determined from the heat exchange capacities of the compounds present in the reaction mixture. $\hat{\mathrm{C}}_{\mathrm{P}_{\mathrm{R}}}=\sum_{i=1}^{N} \mathrm{~W}_{\mathrm{i}} \cdot \hat{\mathrm{C}}_{\mathrm{P}_{\mathrm{i}}}$

$\mathrm{w}_{\mathrm{i}}$ and $\hat{\mathrm{C}}_{\mathrm{P}_{\mathrm{i}}}$ are weight percent and specific heat capacity of compound i. For the sake of simplicity, this parameter will be considered constant, i.e., $2000 \mathrm{~J} /(\mathrm{kg} . \mathrm{K})$ which is the average value for an organic solvent.

- Heat-losses due to evaporation and condensation are neglected,

- It is very important to emphasis the scale-up issue with the determination of A. 


\section{$\underline{\text { Tutorials }}$}

As a representative example, the following reaction system can be considered

$\mathrm{A}+\mathrm{B} \rightarrow \mathrm{C} \quad \mathrm{R}_{1}$

$\mathrm{B} \rightarrow \mathrm{D} \quad \mathrm{R}_{2}$

A researcher has decided to perform this chemical process in a batch reactor with the following thermal modes: isothermal, isoperibolic and adiabatic modes.

The reaction mass is $m_{R}=0.3 \mathrm{~kg}$ and the liquid density is $\rho_{R}=1 \mathrm{~kg} / \mathrm{L}$. The initial concentrations of the different compounds are $C_{A}=C_{B}=2 \mathrm{~mol} / \mathrm{L}$ and $C_{C}=C_{D}=0 \mathrm{~mol} / \mathrm{L}$.

Kinetic data and thermodynamic constants for both reactions are given below

$\mathrm{R}_{1}=\mathrm{k}_{1} \cdot[\mathrm{A}] .[\mathrm{B}]$

$\mathrm{k}_{1}=0.2 \cdot 10^{-2} \mathrm{~L} /(\mathrm{mol} \cdot \mathrm{min})$ at $40^{\circ} \mathrm{C}$

$\mathrm{Ea}_{1}=60 \mathrm{~kJ} / \mathrm{mol}$

$\Delta \mathrm{H}_{\mathrm{R} 1}=-60 \mathrm{~kJ} / \mathrm{mol}$

$\mathrm{R}_{2}=\mathrm{k}_{2} \cdot[\mathrm{B}]$

$\mathrm{k}_{2}=0 \cdot 6 \cdot 10^{-7} \mathrm{~min}^{-1}$ at $40^{\circ} \mathrm{C}$

$\mathrm{Ea}_{2}=200 \mathrm{~kJ} / \mathrm{mol}$

$\Delta \mathrm{H}_{\mathrm{R} 2}=-150 \mathrm{~kJ} / \mathrm{mol}$

The process lasts for $6 \mathrm{~h} 40 \mathrm{~min}$.

The following tasks can be given during the tutorials:

1. Study the effect of reaction temperature on the concentration of the different species and on the heat-flow rate due to chemical reactions and exchanged between the reaction mixture and the heat carrier under isothermal mode. Different reaction temperature from 50 to $100^{\circ} \mathrm{C}$ can be tested. The value of UA is $5 \mathrm{~W} / \mathrm{K}$.

The Matlab code is given in supporting information S3. 
2. Study the effect of the global heat transfer coefficient (UA) on the jacket temperature for a reaction temperature of $90^{\circ} \mathrm{C}$ in isothermal conditions.

3. Study this system under adiabatic mode with an initial reaction temperature of $50^{\circ} \mathrm{C}$, $70^{\circ} \mathrm{C}$ and $100^{\circ} \mathrm{C}$. What is the effect on reaction heat-flow rates, reaction temperature and on the evolution of the concentration of $\mathrm{D}$ ?

4. Study this system under isoperibolic conditions at different jacket temperatures $50^{\circ} \mathrm{C}, 70^{\circ} \mathrm{C}$ and $100^{\circ} \mathrm{C}$. What can you conclude about the heat-flow rates of reactions and exchanged between reaction mixtures and exchanged?

5. What should be the value of A to maintain the reactor in isothermal conditions at $100^{\circ} \mathrm{C}$ with different reaction volume: 5,10 and 100 L? For this question, we wish to have the same evolution of $T_{j}$ than for a volume reaction of $0.4 \mathrm{~L}$. The value of $\mathrm{U}$ is 700 $\mathrm{W} /\left(\mathrm{K} \cdot \mathrm{m}^{2}\right)$.

6. A discussion must take place on the fact that an exothermic reaction does not imply fast reaction heat-flow rates.

Tutorial pedagogy strategy

The instructor should push the students to draw a picture of the different system and the different equations associated to solve out this exercise such as the one represented in Fig. 5.

HERE Fig. 5. 
Response to question 1.

The code (S3-isothermal) allows to follow the concentration of the different species, jacket temperature, and heat-flow rates due to chemical reactions and exchanged with the heat carrier. Students should use the value of kinetic parameters, initial concentrations and reaction temperature. By running the program code at a higher reaction temperature, it can be noticed that the second reaction starts to be more and more important (Fig. 6). Students can also notice that by using the same value for the global heat transfer coefficient UA and by increasing the reaction temperature, the jacket temperature decreases (Fig. 7).

\section{HERE Fig. 6.}

\section{HERE Fig. 7.}

From Fig. 8, one can conclude that the heat-flow rate due to chemical reactions is the same as the one exchanged. This is a way to check whether there are mistakes in the code. As the temperature increases, the heat-flow rate due to chemical reactions increases. One of the most important aspects to highlight is the difference of dynamics between reaction concentration evolution and the heat-flow rate. The instructor should emphasize that heat-flow rate essentially occurs at the beginning of the reaction.

\section{HERE Fig. 8.}

Response to question 2 .

During this question, the instructor can suggest to the students to vary UA from 5 to 20 $\mathrm{W} / \mathrm{K}$. Students should observe that the concentration distribution and the heat-flow rate should not change, but the jacket temperature will be lower at higher UA (Fig. 9). The instructor should explain that the reaction temperature and the jacket temperature can be similar in case of exothermic reactions under isoperibolic conditions if UA is high enough. 


\section{HERE Fig. 9.}

Response to question 3.

Eq 8 should be used for this problem. Under these conditions, it is more evident for the students that the heat-flow rate is a dynamic phenomenon strongly linked to the initial conditions (Fig. 10).

\section{HERE Fig. 10.}

Figs 11. A and B show the concentration evolution of $\mathrm{C}$ and $\mathrm{D}$ with different initial temperature. It can be noticed that as the reaction temperature increase, as the concentration of D increases.

\section{HERE Fig. 11-A.}

\section{HERE Fig. 11-B.}

From Fig. 12, it is possible to determine some safety criteria such as the final temperature reached by the system and the time to reach this final temperature.

It can be worth to give additional exercises such as to investigate the same system under adiabatic conditions by neglecting the second reaction. The goal of this additional exercise is to demonstrate that the difference $\left(\mathrm{T}_{\mathrm{r}}(\mathrm{Final})-\mathrm{T}_{\mathrm{r}}(0)\right)$ is the same for a single reaction (Fig. 13). The concepts of adiabatic temperature rise $\Delta \mathrm{T}_{\mathrm{ad}}$ and time to maximum rate under adiabatic condition $\mathrm{TMR}_{\mathrm{ad}}$ can be introduced. The goal of this additional exercise is to highlight the case of a multiple reaction system. Students should be aware that in the presence of a single reaction, the adiabatic temperature 
rise $\Delta \mathrm{T}_{\mathrm{ad}}$ is the same at any initial reaction temperature. This is not the case in presence of composite reactions.

\section{HERE Fig. 12.}

\section{HERE Fig. 13.}

Response to question 4.

At this moment, one can understand the difference between isothermal and adiabatic modes. At the end of this question, one should ask to the students to compare the same system under isothermal mode at $90^{\circ} \mathrm{C}$, under adiabatic mode with $\operatorname{Tr}(0)=90{ }^{\circ} \mathrm{C}$ and under isoperibolic mode with $\mathrm{Tj}=90^{\circ} \mathrm{C}$.

One should plot the evolution of the reaction and jacket temperatures (Fig. 14) and the evolution of the concentration distribution (Fig. 15).

HERE Fig. 14.

\section{HERE Fig. 15.}

The goal of Figs 14 and 15 is to highlight the difference between these thermal modes.

Response to question 5.

By running the program code at $100{ }^{\circ} \mathrm{C}$ and with a reaction volume of $0.4 \mathrm{~L}$, it is possible to determine the difference $\left(\mathrm{T}_{\mathrm{j}}-\mathrm{T}_{\mathrm{r}}\right)$. Then, it is possible to plot the graph on Fig. 16 and to know the needed surface area (slope of each curve) for each volume.

\section{HERE Fig. 16.}

The objective of this exercise is to illustrate the scale-up issue. Cylindrical batch reactors as illustrated by Fig. 17 are considered.

\section{HERE Fig. 17.}




\section{HERE Table 1.}

From Table 1, it can be noticed that for a pilot batch reactor the external surface area is not big enough to ensure isothermal conditions, and the addition of an internal cooling coil might be considered.

Response to question 6.

This discussion should take place because it can be the source of misunderstanding. Indeed, a process can be performed under an isoperibolic mode and the reaction temperature can be stable. There are two reasons for that:

- Reaction heat-flow rate, which is the product of reaction rate times reaction enthalpy, is low,

- The global heat transfer coefficient is high enough.

By keeping the same reaction system, one can increase the global heat transfer coefficient (Fig. 18). It can be noticed that when UA is equal to $90 \mathrm{~W} / \mathrm{K}$, the reaction temperature increase is not significant, thus one can consider the system as isothermal.

\section{HERE Fig. 18.}

The other discussion is how to vary the value of UA from a design point of view. The instructor should first remind that the heat exchange surface area can be increased by using some internal coils, where the heat carrier fluid circulates. The value of $U$ depends of the nature of the reaction mixture (composition, temperature, conductivity) and of the heat carrier fluid (conductivity, composition, temperature, velocity) (Lavanchy (2005)). 


\section{INTRODUCTION TO THERMAL SAFETY ASSESSMENT}

At this moment of the course, students have a good knowledge of the coupling of mass and energy balances; they know how to determine the heat-flow rate and how to simulate quantitative results, i.e., the progress of concentrations and temperature in the reactor. Furthermore, they understand the methodology in case of composite exothermic reactions. This is the perfect timing to introduce some concepts of thermal safety as described in the book of F. Stoessel (2008):

-thermal runaway with Semenov diagram,

-influence of UA,

-critical temperature,

-concept of $\mathrm{TMR}_{\mathrm{ad}}$ and $\Delta \mathrm{T}_{\mathrm{ad}}$.

- Tnr

It is wiser to introduce these concepts with the corresponding approximation after the lecture on mass and energy balances coupling. Indeed, several safety criteria have been determined by using zero order approximation (Leveneur et al. (2015)), which is considered to be the worst case scenario.

In case of thermal runaway, the heat-flow rate released by chemical reactions is higher than the heat-flow rate absorbed by heat carrier. The instructor should insist that some chemical systems can evolve under these conditions (adiabatic or isoperibolic) becase the secondary reactions are not trigger and/or the reactor was designed for such conditions. . 
It is easier to understand the Semenov curves by using a zero-order reaction under isoperibolic mode (Fig. 19). A stable region occur when $\mathrm{q}_{\mathrm{rx}}<\mathrm{q}_{\text {exch. }}$. The students should observe that the heat-flow rate due to chemical reactions increases exponentially, whereas the heat-flow rate exchanged increases linearly.

\section{HERE Fig. 19.}

When a reactor is operated at a critical cooling medium temperature (Tc), an infinitely small increase of the cooling medium temperature leads to a runaway situation. This could have a dramatic effect if the secondary reactions are triggered. Students should be aware that if heat transfer coefficient (UA) diminishes, due to fouling or inappropriate scale-up, then a runaway situation can appear.

At the critical temperature, we obtain

$\frac{d \mathrm{q}_{r x}}{d \mathrm{t}}=\frac{d \mathrm{q}_{e x c h}}{d \mathrm{t}}$

For a zero-order reaction, the stability is reached if

$$
\Delta \mathrm{T}_{\text {crit }}=\mathrm{T}_{\text {crit }}-\mathrm{T}_{\mathrm{R}} \geq \frac{\mathrm{R} \cdot \mathrm{T}_{\text {crit }}^{2}}{\mathrm{E}_{\mathrm{a}}} \text { with } \mathrm{T}_{\text {crit }}=\frac{\mathrm{E}_{\mathrm{a}}}{2 \cdot R}\left(1 \pm \sqrt{1-\frac{4 \cdot \mathrm{R} \cdot \mathrm{T}_{0}}{\mathrm{E}_{\mathrm{a}}}}\right)
$$

Students should be aware that in the presence of a complex reaction system, a numerical approach is inevitable.

The other important concept is the time of no return (Tnr). If the system shifts to adiabatic conditions due to a failure for a period of time, then even if the cooling system is coped, there is no possibility to return to the initial thermal mode.

A proper way to introduce the different safety criteria such as $\mathrm{TMR}_{\mathrm{ad}}$ or $\Delta \mathrm{T}_{\mathrm{ad}}$ is by using the example of an exothermic chemical system in a batch reactor under isothermal conditions. 


\section{HERE Fig. 20.}

Fig. 20 illustrates the different safety criteria during a cooling failure, e.g., circulation of the heat carrier is stopped. Under normal conditions, reactants are heating until the desired temperature, after which the reaction mixture is maintained constant (isothermal mode), and at the end of the process, the reaction mixture is cooled down. In case of a cooling failure, the system can shift from isothermal to adiabatic mode. The first temperature increase is due to the synthesis reactions (desired and un-desired) and the second temperature increase is due the secondary reactions producing noncondensable products. If the secondary reactions are trigger, there is a risk of explosion due to the overpressure inside the reactor. For this reason, it is recommended to use a reflux condenser or a rupture disk.

There are several kinds of calorimeters to study a chemical system under adiabatic conditions allowing to follow the evolution of the pressure in the gas phase. To model such system, one should consider the liquid-gas mass transfer, the vapour liquid equilibrium, and the kinetics of secondary reactions. The knowledge of secondary reactions can be difficult and requiring the use of on-line analytical techniques (Leveneur et al. (2007)).

At this moment of the lecture, the instructor can present a slide showing the different type of calorimeter and how these parameters can be measured or determined.

From Fig. 20, there are different messages to deliver:

- $\mathrm{TMR}_{\mathrm{ad}}$ and $\Delta \mathrm{T}_{\mathrm{ad}}$ represent the probability and severity of the risk,

- The time and period of cooling failure can lead to different consequences, if the cooling failure occur at the beginning of the reaction, then the severity can be high,

- Fig. 20 is a pedagogic image, there is not a distinct plateau between the synthesis and secondary reactions. 
- On a reactor system, there is some rupture disk to avoid the overpressure or some emergency relief system.

An example will be treated to illustrate this figure for the project.

By assuming a zero-order reaction, one can calculate the $\mathrm{TMR}_{\mathrm{ad}}$ as:

$\mathrm{TMR}_{\mathrm{ad}}=\frac{\mathrm{C}_{\mathrm{P}}^{\prime} \cdot \mathrm{R} \cdot \mathrm{T}_{\mathrm{ref}}^{2}}{\mathrm{q}_{\mathrm{rx}, \text { ref }} \cdot \mathrm{E}_{\mathrm{a}}}$

The two other safety criteria important to be introduced are:

-MTT is the maximum temperature for technical reason, which is linked to the resistance of the reactor structure. This criteria is usually the boiling point of the reaction mixture.

$-\mathrm{T}_{\mathrm{D} 24}$ is the temperature at which $\mathrm{TMR}_{\mathrm{ad}}$ is 24 hours. This criteria is complicated to determine accurately and need the use of low $\varphi$-factor calorimeter. For that reason, eq (12) is often used.

By knowing all these criteria, it is possible to rank the thermal risk of a chemical process (Stoessel (2008)). One should really insist on the fact that usually worst case scenario is considered, i.e., full reactant accumulation, batch reactor and adiabatic conditions.

Introducing this approach without a complete upgrading of mass and energy balances can lead the future chemical engineers to make some wrong assessment or decision. Based on this introduction on process safety, the process safety course can start by discussing about the different thermal techniques to determine the safety criteria, the Stoessel criticality classes, the calculation of vent size, the early detection...etc. The study of different industrial accidents can be done (Al-shanini et al. (2014)). 


\section{THERMAL RISK PROJECT}

The following project can be introduced at the end of the course to master the numerical and the safety aspects.

A company wants to produce a compound C from A and B under isothermal conditions in a batch reactor.

The total mass of the reaction mixture is $6 \mathrm{~kg}$ for a volumetric mass of $1 \mathrm{~L} / \mathrm{kg}$. The heat capacity of the reaction mixture is constant during the process $(2 \mathrm{~kJ} /(\mathrm{kg} \cdot \mathrm{K}))$.

However, two other side reactions appear in the process:

$$
\begin{array}{ll}
\mathrm{A}+\mathrm{B} \rightarrow \mathrm{C} & \mathrm{R}_{1} \\
\mathrm{~B} \rightarrow \mathrm{D} & \mathrm{R}_{2} \\
\mathrm{C}+\mathrm{C} \rightarrow \mathrm{E} & \mathrm{R}_{3}
\end{array}
$$

Kinetic data and thermodynamic constants for both reactions are listed below

$\mathrm{R}_{1}=\mathrm{k}_{1} \cdot[\mathrm{A}] \cdot[\mathrm{B}]$

$\mathrm{k}_{1}=0 \cdot 2 \cdot 10^{-4} \mathrm{~L} /(\mathrm{mol} \cdot \mathrm{min})$ at $40^{\circ} \mathrm{C}$

$\mathrm{Ea}_{1}=60 \mathrm{~kJ} \cdot \mathrm{mol}^{-1}$

$\Delta \mathrm{H}_{\mathrm{R} 1}=-60 \mathrm{~kJ} \cdot \mathrm{mol}^{-1}$

$\mathrm{R}_{2}=\mathrm{k}_{2} \cdot[\mathrm{B}]$

$\mathrm{k}_{2}=0.6 \cdot 10^{-9} \mathrm{~min}^{-1}$ at $40^{\circ} \mathrm{C}$

$\mathrm{Ea}_{2}=80 \mathrm{~kJ} / \mathrm{mol}$

$\Delta \mathrm{H}_{\mathrm{R} 2}=-100 \mathrm{~kJ} / \mathrm{mol}$

$\mathrm{R}_{3}=\mathrm{k}_{3} \cdot[\mathrm{C}]^{2}$

$\mathrm{k}_{3}=1 \cdot 0 \cdot 10^{-13} \mathrm{~L} /(\mathrm{mol} \cdot \mathrm{min})$ at $40^{\circ} \mathrm{C}$

$\mathrm{Ea}_{3}=260 \mathrm{~kJ} / \mathrm{mol}$

$\Delta \mathrm{H}_{\mathrm{R} 3}=-250 \mathrm{~kJ} / \mathrm{mol}$ 
The company purchased a cooling system to maintain the reaction temperature at $130^{\circ} \mathrm{C}$ with $\mathrm{UA}=5 \mathrm{~W} / \mathrm{K}$. In case of malfunction, there is another cooling system working at $130^{\circ} \mathrm{C}$. The initial concentrations of $\mathrm{A}$ and $\mathrm{B}$ are $3 \mathrm{~mol} / \mathrm{L}$; and the concentrations for the other compounds are $0 \mathrm{~mol} / \mathrm{L}$.

HERE Fig. 21.

1. Determine the reaction time to reach the maximum production of compound $\mathrm{C}$ under isothermal conditions and plot the evolution of the reaction and jacket temperature.

2. The maximum temperature for technical reasons is $300^{\circ} \mathrm{C}$. Determine the adiabatic temperature rise and $\mathrm{TMR}_{\mathrm{ad}}$ for this system for the worst case scenario.

3. During the process under normal conditions at $130^{\circ} \mathrm{C}$, under isothermal conditions, a cooling failure occur at time 10000 seconds for 1700 seconds. The operator manages to fix the heat carrier fluid circulation problem, but the cooling system still did not work. Thus, the jacket temperature was constant and equal to $130^{\circ} \mathrm{C}$ at time 11700 s. In such conditions, is it possible to have an explosion if the process is schedule to last 300 minutes?

4. Based on the previsous accident, determine with these operating conditions the time of no return.

5. Which are the consequences of the incident on the product distribution?

Due to the space limitation of the journal, the reponses to the problem are provided in supplementary (S4). 


\section{CONCLUSION}

We presented a pedagogical approach to present the strong coupling between mass and energy balances. It is important for undergraduate or master students to take into account the different heat-flow rates at stake in a chemical reactor and to differentiate the different thermal modes before to start a course on process safety. We have used some exercises based on numerical methods where the students should plot the evolution of the reaction temperature, jacket temperature and the heat-flow rates exchanged with the hat carrier and released by the chemical reactions.

For the students, this pedagogical approach is time-depending. Indeed, they have to be familiar with the code environment and understand the phenomenology. However, the 3-weeks project give them the time to test the code and to understand the project. We have also noticed that the students were thinking to develop some safety barrier such as the introduction of an emergency cooling system.

The knowledge of the different notions taught in this course will help the undergraduate or master students to understand and to be critical vis-à-vis of the simplification done during the risks assessment of a chemical process.

The process safety course can start by presenting the different thermal equipment and calorimeters used to determine the safety criteria, how to take into account the evolution of pressure, the safety barrier and the methodology for risks assessment. 
ACKNOWLEDGMENTS

This work is a part of the activities of the Johan Gadolin Process Chemistry Centre

(PCC), a Centre of Excellence financed by Åbo Akademi University and Academy of Finland. 


\section{LIST OF FIGURES}

Fig. 1. Schematic view of the pedagogical approach.

Fig. 2. Mass balance for chemical reactors.

Fig. 3. Energy balance for chemical reactors.

Fig. 4. Illustration of different thermal modes for a batch reactor.

Fig. 5. Presentation of the problem at the blackboard.

Fig. 6. Effect of reaction temperature on the concentration of compound C and D.

Fig. 7. Effect of reaction temperature on jacket temperature under isothermal conditions.

Fig. 8. Effect of reaction temperature on heat-flow rate under isothermal conditions.

Fig. 9. Effect of UA on the jacket temperature under isothermal condition with $\mathrm{Tj}=90$ ${ }^{\circ} \mathrm{C}$.

Fig. 10. Logarithm of heat-flow rate of reactions evolution at different initial reaction temperature.

Fig. 11-A. Evolution of the concentration of $\mathrm{C}$ with different initial reaction temperatures.

Fig. 11-B. Evolution of the concentration of D with different initial reaction temperature.

Fig. 12. Reaction temperature evolution with different initial reaction temperatures.

Fig. 13. Evolution of temperature in case of neglecting the second reaction

Fig. 14. Evolution of concentration for the three modes.

Fig. 15. Evolution of temperature for the three modes.

Fig. 16. Determination of the surface area.

Fig. 17. Reactor dimension.

Fig. 18. Influence of UA on reaction temperature under isoperibolic mode with $\mathrm{Tj}=90$ ${ }^{\circ} \mathrm{C}$.

Fig. 19. Semenov curves. 
Fig. 20. Cooling failure scenario for an exothermic reaction system in a batch reactor.

Fig. 21. Reactor system.

\section{LIST OF TABLES}

Table 1. Features of the different reactors. 


\section{REFERENCES}

Al-shanini, A., Ahmad, A., Khan, F., 2014. Accident modelling and analysis in process industries. Journal of Loss Prevention in the Process Industries 32, 319-334.

doi:10.1016/j.jlp.2014.09.016

Antunes, B.M., Cardoso, S.P., Silva, C.M., Portugal, I., 2011. Kinetics of Ethyl Acetate Synthesis Catalyzed by Acidic Resins. J. Chem. Educ. 88, 1178-1181.

doi: $10.1021 /$ ed $100471 \mathrm{j}$

Coker, A.K., 2001. Modeling of Chemical Kinetics and Reactor Design, 1st ed. Gulf Professional Publishing.

Dee, S.J., Cox, B.L., Ogle, R.A., 2015. Process safety in the classroom: The current state of chemical engineering programs at US universities. Proc. Safety Prog. 34, 316-319. doi: $10.1002 /$ prs. 11732

Dixon, D.J., Kohlbrand, H.T., 2015. Lending industrial experience through reactive hazard examples in university safety instruction. Proc. Safety Prog. 34, 360-367. doi: $10.1002 /$ prs. 11785

Eizenberg, S., Shacham, M., Brauner, N., 2006. Combining HAZOP with dynamic simulation-Applications for safety education. Journal of Loss Prevention in the Process Industries 19, 754-761.

doi:10.1016/j.jlp.2006.07.002

Favre, E., Falk, V., Roizard, C., Schaer, E., 2008. Trends in chemical engineering education: Process, product and sustainable chemical engineering challenges.

Education for Chemical Engineers 3, e22-e27.

doi:10.1016/j.ece.2007.12.002

Finlayson, B.A., 2006. Introduction to Chemical Engineering Computing, 1st ed. John Wiley \& Sons, Inc. 
Fogler, H.S., 2016. Elements of Chemical Reaction Engineering, 5th ed. Prentice Hall Inc.

Lavanchy, F., 2005. Development of reaction calorimetry applied to supercritical $\mathrm{CO}_{2}$ and methanol- $\mathrm{CO}_{2}$ critical mixture.

doi: $10.5075 /$ epfl-thesis-3228

Law, J.V., 2013. Numerical Methods for Chemical Engineers Using Excel, VBA, and MATLAB, 1st ed. CRC Press.

Leveneur, S., Estel, L., Crua, C., 2015. Thermal risk assessment of vegetable oil epoxidation. J Therm Anal Calorim 122, 795-804.

doi: $10.1007 /$ s 10973-015-4793-8

Leveneur, S., Salmi, T., Musakka, N., Wärnå, J., 2007. Kinetic study of decomposition of peroxypropionic acid in liquid phase through direct analysis of decomposition products in gas phase. Chemical Engineering Science, 19th International Symposium on Chemical Reaction Engineering - From Science to Innovative Engineering ISCRE-19 62, 5007-5012. doi:10.1016/j.ces.2006.12.040

Leveneur, S., Thönes, M., Hébert, J.-P., Taouk, B., Salmi, T., 2012. From Kinetic Study to Thermal Safety Assessment: Application to Peroxyformic Acid Synthesis. Ind. Eng. Chem. Res. 51, 13999-14007. doi: $10.1021 /$ ie3017847 Levenspiel, O., 1999. Chemical Reaction Engineering. Ind. Eng. Chem. Res. 38, 41404143. doi: $10.1021 /$ ie990488g

Lindfors, L.-E., 1971. An undergraduate experiment in chemical engineering reactor kinetics. J. Chem. Educ. 48, 472.

doi:10.1021/ed048p472 
Mlasi, B., Glasser, D., Hildebrandt, D., 2015. Kinetics of the Decomposition of Hydrogen Peroxide in Acidic Copper Sulfate Solutions. Ind. Eng. Chem. Res. 54, 5589-5597. doi:10.1021/acs.iecr.5b00642

Perrin, L., Laurent, A., 2008. Current situation and future implementation of safety curricula for chemical engineering education in France. Education for Chemical Engineers 3, e84-e91.

doi:10.1016/j.ece.2008.08.001

Rawlings, J.B., Ekerdt J.G., 2013. Chemical Reactor Analysis and Design

Fundamentals, 2nd ed. Nob Hill Pub.

Salmi, T.O., Mikkola J.-P., Wärnå, J.P., 2010. Chemical Reaction Engineering and Reactor Technology, 1st ed. CRC Press.

Shallcross, D.C., 2013. Safety education through case study presentations. Education for Chemical Engineers 8, e12-e30.

doi:10.1016/j.ece.2012.10.002

Spicer, T.O., Willey, R.J., Crowl, D.A., Smades, W., 2013. The safety and chemical engineering education committee-broadening the reach of chemical engineering process safety education. Proc. Safety Prog. 32, 113-118.

doi: $10.1002 /$ prs. 11594

Taipa, M.Â., Azevedo, A.M., Grilo, A.L., Couto, P.T., Ferreira, F.A.G., Fortuna, A.R.M., Pinto, I.F., Santos, R.M., Santos, S.B., 2015. Student Collaboration in a Series of Integrated Experiments To Study Enzyme Reactor Modeling with Immobilized CellBased Invertase. J. Chem. Educ. 92, 1238-1243.

doi: $10.1021 /$ ed500842p

Stoessel, F., 2008. Thermal Safety of Chemical Processes: Risk Assessment and Process Design, first ed. Wiley. 
Villermaux, J., 1999. Génie de la Réaction Chimique : Conception et Fonctionnement des Réacteurs, 2ème éd. Tec \& Doc Lavoisier.

Willey, R.J., Fogler, H.S., Cutlip, M.B., 2011. The Integration of Process Safety into a Chemical Reaction Engineering Course: Kinetic Modeling of the T2 Incident. Proc. Safety Prog. 30, 39-44.

doi $10.1002 /$ prs. 10431 


\section{HIGHLIGHTS}

- Introduction to the different thermal modes: isothermal, isoperibolic and adiabatic

- Numerical approach to illustrate mass \& energy coupling in chemical reactors

- Determination of safety criteria based on zero-order assumption and by simulation 


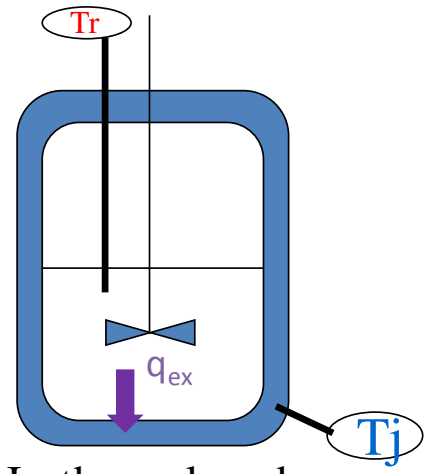

Isothermal mode

$\mathrm{T}_{\mathrm{R}}=$ constant

$$
\mathrm{q}_{\mathrm{rx}}=-\mathrm{q}_{\mathrm{exch}}
$$

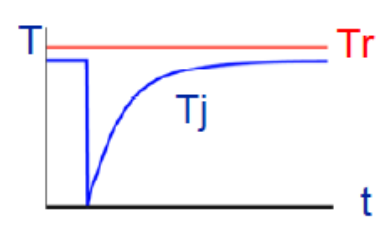

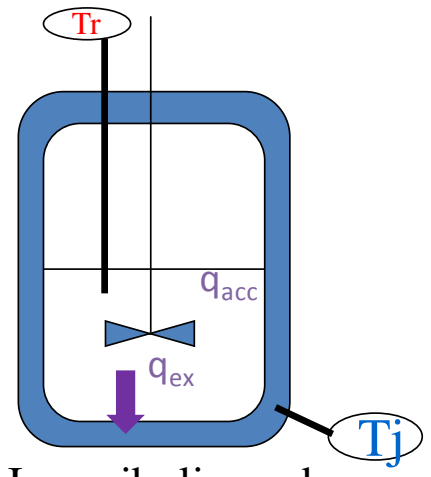

Isoperibolic mode $\mathrm{T}_{\mathrm{j}}=$ constant
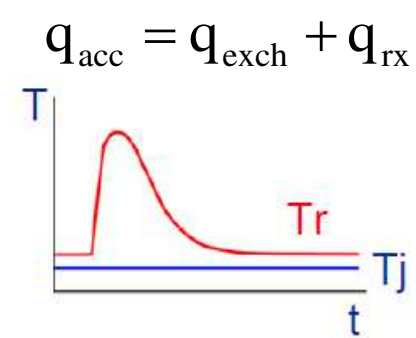

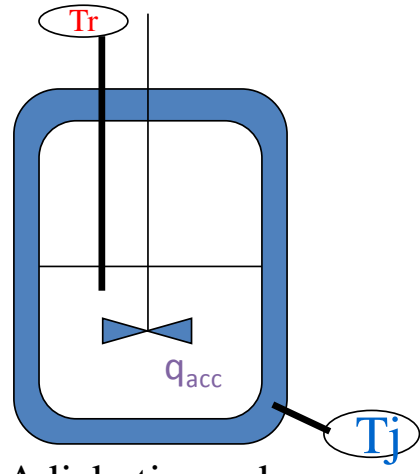

Adiabatic mode

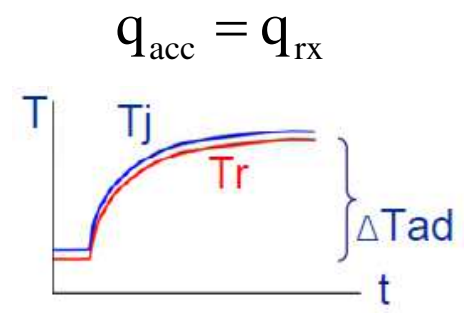


Table 1. Features of the different reactors.

\begin{tabular}{|c|c|c|c|c|}
\hline Volume $(\mathrm{L})$ & Diameter $(\mathrm{m})$ & Height $(\mathrm{m})$ & Surface area $\mathrm{m}^{2}$ & ${\text { Required surface } \text { area }^{2}}^{2}$ \\
\hline 0.4 & 0.04 & 0.29 & 0.04 & 0.01 \\
\hline 5 & 0.15 & 0.30 & 0.16 & 0.18 \\
\hline 10 & 0.15 & 0.60 & 0.30 & 0.36 \\
\hline 100 & 0.30 & 1.50 & 1.48 & 3.57 \\
\hline
\end{tabular}




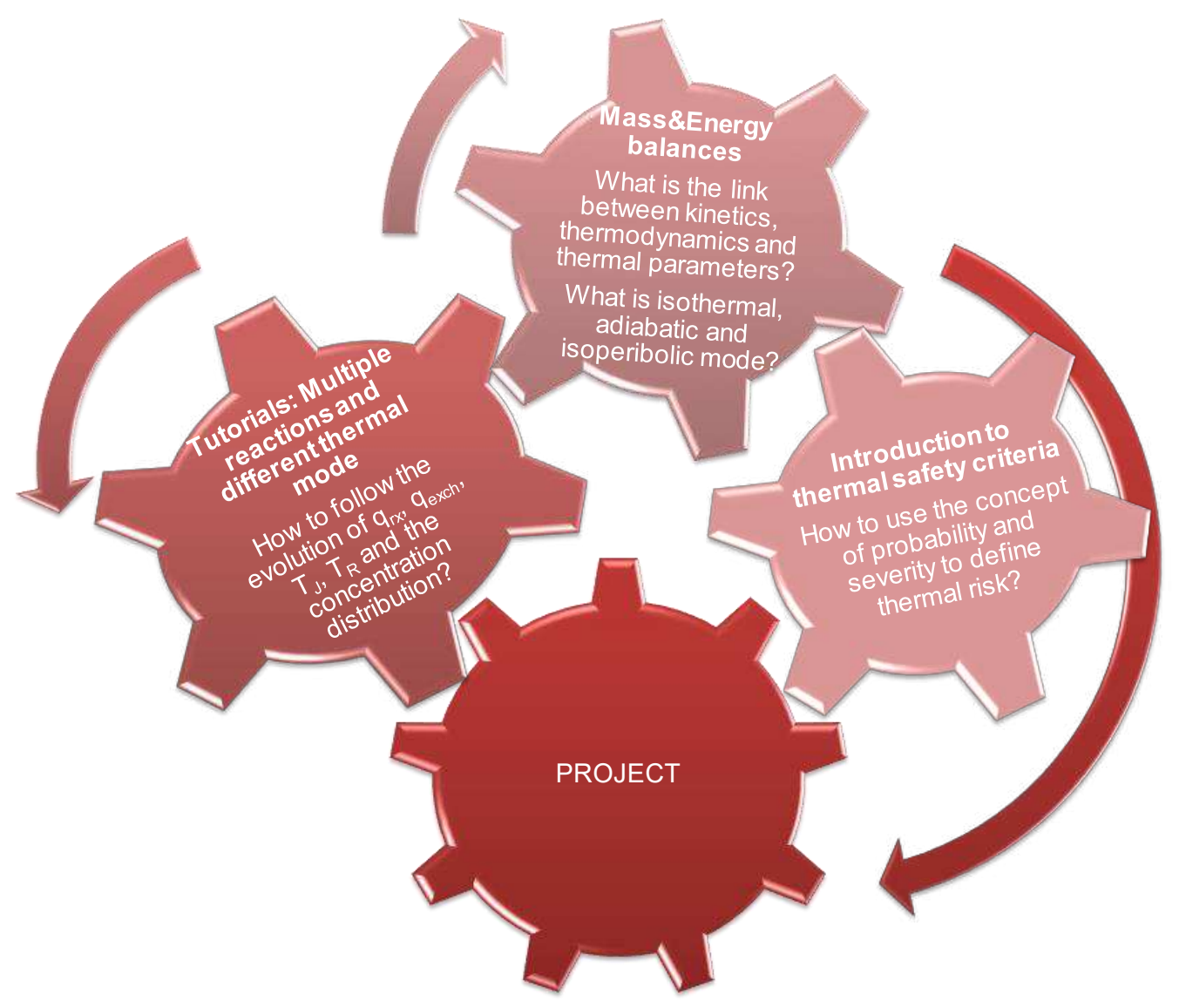

Fig. 1. Schematic view of the pedagogical approach. 


\section{Batch reactor}

$V_{R} \sum_{i} v_{\mathrm{ij}} \cdot \mathrm{R}_{\mathrm{i}}=\frac{\mathrm{dn}_{\mathrm{j}}}{\mathrm{dt}}$

Continuous tubular reactor
Semi-batch reactor

$$
\frac{\mathrm{dn}_{\mathrm{j}}}{\mathrm{dt}}=\mathrm{F}_{\mathrm{j}, \text { inlet }}+\mathrm{r}_{\mathrm{j}} \cdot \mathrm{V}_{\mathrm{R}}=\mathrm{F}_{\mathrm{j}, \text { inlet }}+\sum_{i=1}^{n_{r}} v_{i j} \cdot \mathrm{R}_{\mathrm{i}} \cdot \mathrm{V}_{\mathrm{R}}
$$$$
7 \mathrm{~V}_{\mathrm{R}}=\mathrm{V}_{\mathrm{R}, 0}+\int_{0}^{\mathrm{t} \text { add }} \mathrm{Q}_{\text {inlet }} \mathrm{dt}
$$

\section{Continuous stirred tank reactor}

$\frac{\mathrm{dn}_{\mathrm{j}}}{\mathrm{dt}}=\mathrm{F}_{\mathrm{j}, \text { inlet }}-\mathrm{F}_{\mathrm{j}, \text { outlet }}+\mathrm{r}_{\mathrm{j} \cdot} \cdot \mathrm{V}_{\mathrm{R}}=\mathrm{F}_{\mathrm{j}, \text { inlet }}-\mathrm{F}_{\mathrm{j}, \text { outlet }}+\sum^{n_{r}} v_{i j} \cdot \mathrm{R}_{\mathrm{i}} \cdot \mathrm{V}_{\mathrm{R}}$

Under steady-state

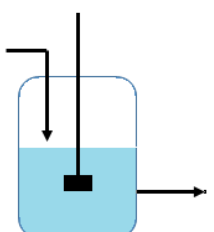

Fig. 2. Mass balance for chemical reactors. 


\section{Batch reactor}

$\mathrm{V}_{\mathrm{R}} \cdot \rho_{\mathrm{R}} \cdot \hat{\mathrm{C}}_{\mathrm{P}_{\mathrm{R}}} \cdot \frac{\mathrm{dT}_{\mathrm{R}}}{\mathrm{dt}}-\alpha \cdot \mathrm{T}_{\mathrm{R}} \cdot \mathrm{V}_{\mathrm{R}} \cdot \frac{\mathrm{dP_{ \textrm {R } }}}{\mathrm{dt}}+\sum_{\mathrm{i}=1}^{\mathrm{n}_{\mathrm{R}}} \Delta \mathrm{H}_{\mathrm{Ri}} \cdot \mathrm{R}_{\mathrm{i}} \cdot \mathrm{V}_{\mathrm{R}}=\mathrm{q}_{\text {exch }}$

\section{Semi-batch reactor}

$$
\mathrm{V}_{\mathrm{R}} \cdot \rho_{\mathrm{R}} \cdot \hat{\mathrm{C}}_{\mathrm{P}} \cdot \frac{\mathrm{dT}_{\mathrm{R}}}{\mathrm{dt}}-\alpha \cdot \mathrm{T}_{\mathrm{R}} \cdot \mathrm{V}_{\mathrm{R}} \cdot \frac{\mathrm{dP}_{\mathrm{R}}}{\mathrm{dt}}-\mathrm{q}_{\text {exch }}=\sum_{\mathrm{j}} \mathrm{C}_{\mathrm{j}, \text { inlet }} \cdot \mathrm{Q}_{\mathrm{j}, \text { inlet }} \cdot \overline{\mathrm{C}}_{\mathrm{Pj}} \cdot\left(\mathrm{T}_{\mathrm{Feed}}-\mathrm{T}_{\mathrm{R}}\right)-\sum_{i=1}^{n_{R}} \Delta \mathrm{H}_{\mathrm{Ri}} \cdot \mathrm{R}_{\mathrm{i}} \cdot \mathrm{V}_{\mathrm{R}}
$$

\section{Continuous tubular reactor}

$$
\begin{aligned}
& \sum_{j=1}^{n_{R}} \mathrm{C}_{\mathrm{j}} \cdot \mathrm{C}_{\mathrm{Pj}} \frac{\partial \mathrm{T}_{\mathrm{R}}}{\partial \mathrm{t}}-\frac{\alpha \cdot \mathrm{V}_{\mathrm{R}} \cdot \mathrm{T}_{\mathrm{R}} \cdot \frac{\partial \mathrm{P}_{\mathrm{R}}}{\partial \mathrm{t}}}{\partial \mathrm{V}_{\mathrm{R}}}-\frac{\partial \mathrm{q}_{\text {exch }}}{\partial \mathrm{V}_{\mathrm{R}}}=\left(\sum_{j=1}^{n_{R}} \mathrm{~F}_{\mathrm{j}} \cdot \mathrm{C}_{\mathrm{Pj}}\right) \frac{\partial \mathrm{T}_{\mathrm{R}}}{\partial \mathrm{V}_{\mathrm{R}}}-\sum_{i=1}^{n_{R}} \Delta \mathrm{H}_{\mathrm{Ri}} \cdot \mathrm{R}_{\mathrm{i}} \\
& \text { with } \left.\alpha=\frac{1}{\mathrm{~V}_{\mathrm{R}}} \cdot\left(\frac{\partial \mathrm{V}_{\mathrm{R}}}{\partial \mathrm{T}_{\mathrm{R}}}\right)_{\mathrm{P}_{\mathrm{n}} \mathrm{n}_{j}} \text { and } \dot{\mathrm{q}}_{\mathrm{exch}}=\mathrm{UA}\left(\mathrm{T}_{\mathrm{f}}-\mathrm{T}_{\mathrm{R}}\right)\right)
\end{aligned}
$$

\section{Continuous stirred tank reactor}

$$
\mathrm{V}_{\mathrm{R}} \cdot \rho_{\mathrm{R}} \cdot \hat{\mathrm{C}}_{\mathrm{P}} \cdot \frac{\mathrm{dT}_{\mathrm{R}}}{\mathrm{dt}}-\alpha \cdot \mathrm{T}_{\mathrm{R}} \cdot \mathrm{V}_{\mathrm{R}} \cdot \frac{\mathrm{dP}_{\mathrm{R}}}{\mathrm{dt}}-\mathrm{q}_{\mathrm{exch}}=\sum_{\mathrm{j}} \mathrm{C}_{\mathrm{j} \text {, inlet }} \cdot \mathrm{Q}_{\mathrm{j}, \text { inlet }} \cdot \overline{\mathrm{C}}_{\mathrm{Pj}} \cdot\left(\mathrm{T}_{\mathrm{Feed}}-\mathrm{T}_{\mathrm{R}}\right)-\sum_{i=1}^{n_{R}} \Delta \mathrm{H}_{\mathrm{Ri}} \cdot \mathrm{R}_{\mathrm{i}} \cdot \mathrm{V}_{\mathrm{R}}
$$

Fig. 3. Energy balance for chemical reactors. 


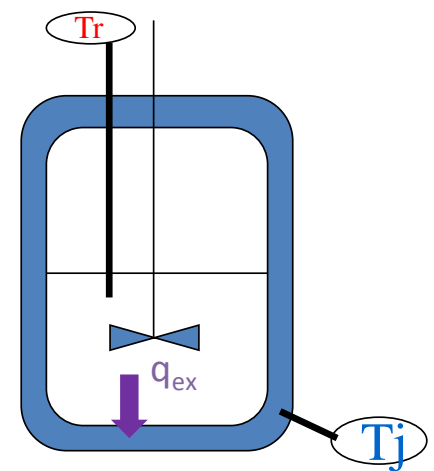

Isothermal mode

$\mathrm{T}_{\mathrm{R}}=$ constant

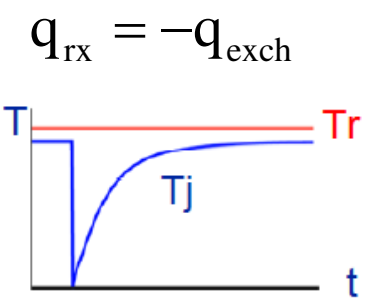

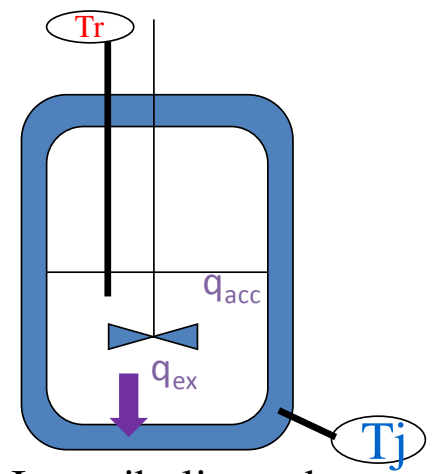

Isoperibolic mode $\mathrm{T}_{\mathrm{j}}=$ constant

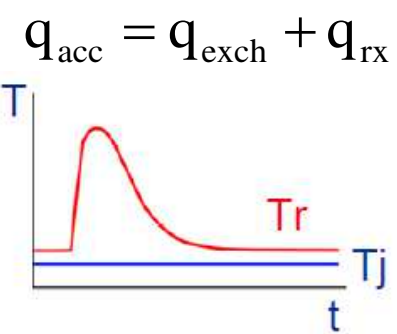

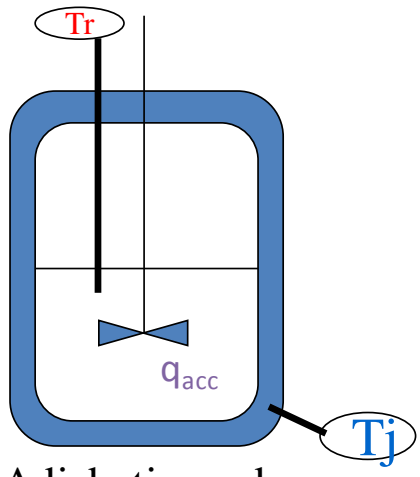

Adiabatic mode

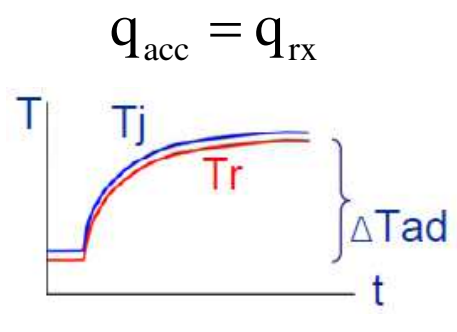

Fig. 4. Illustration of different thermal modes for a batch reactor. 


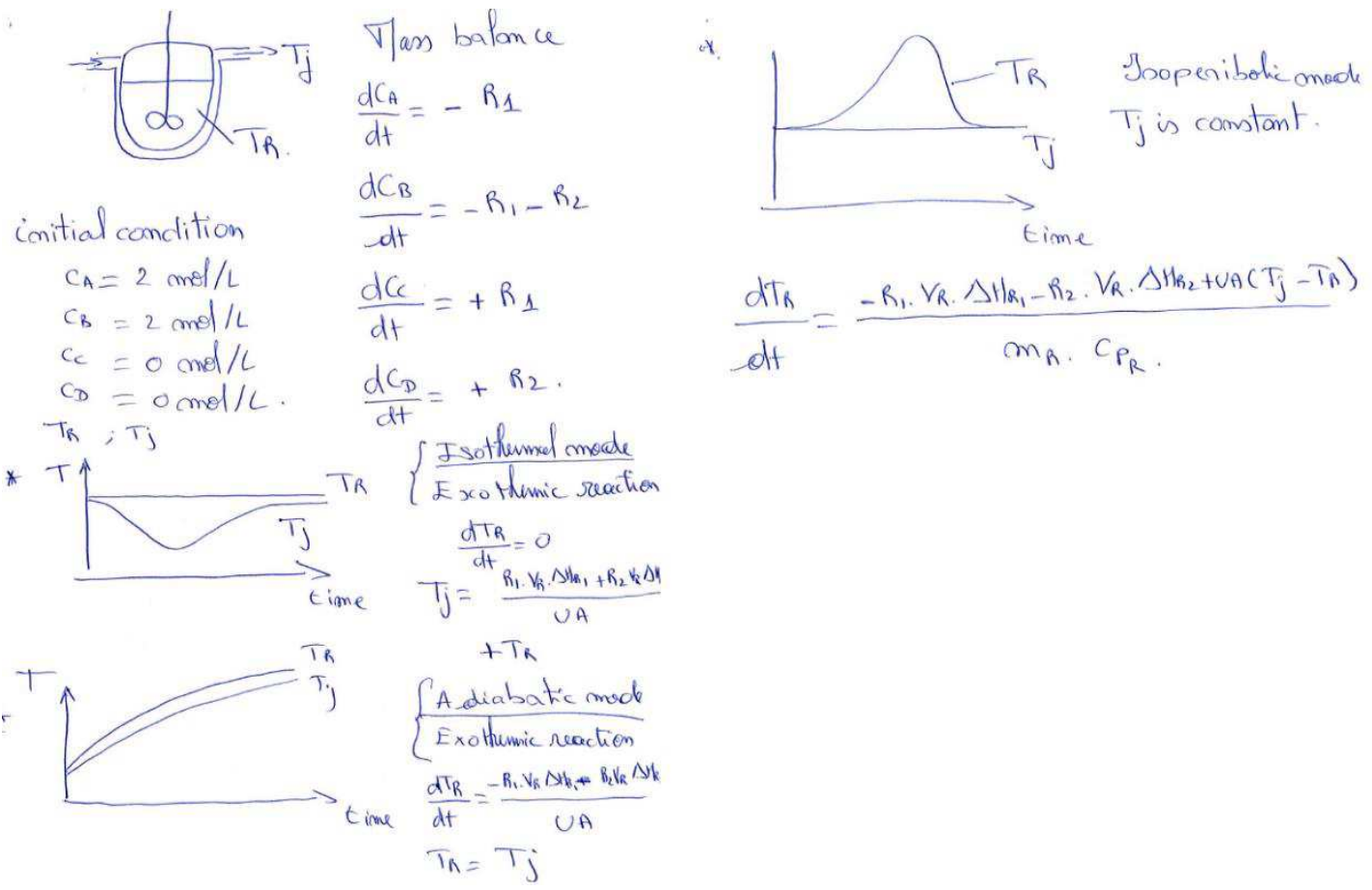

Fig. 5. Presentation of the problem at the blackboard. 


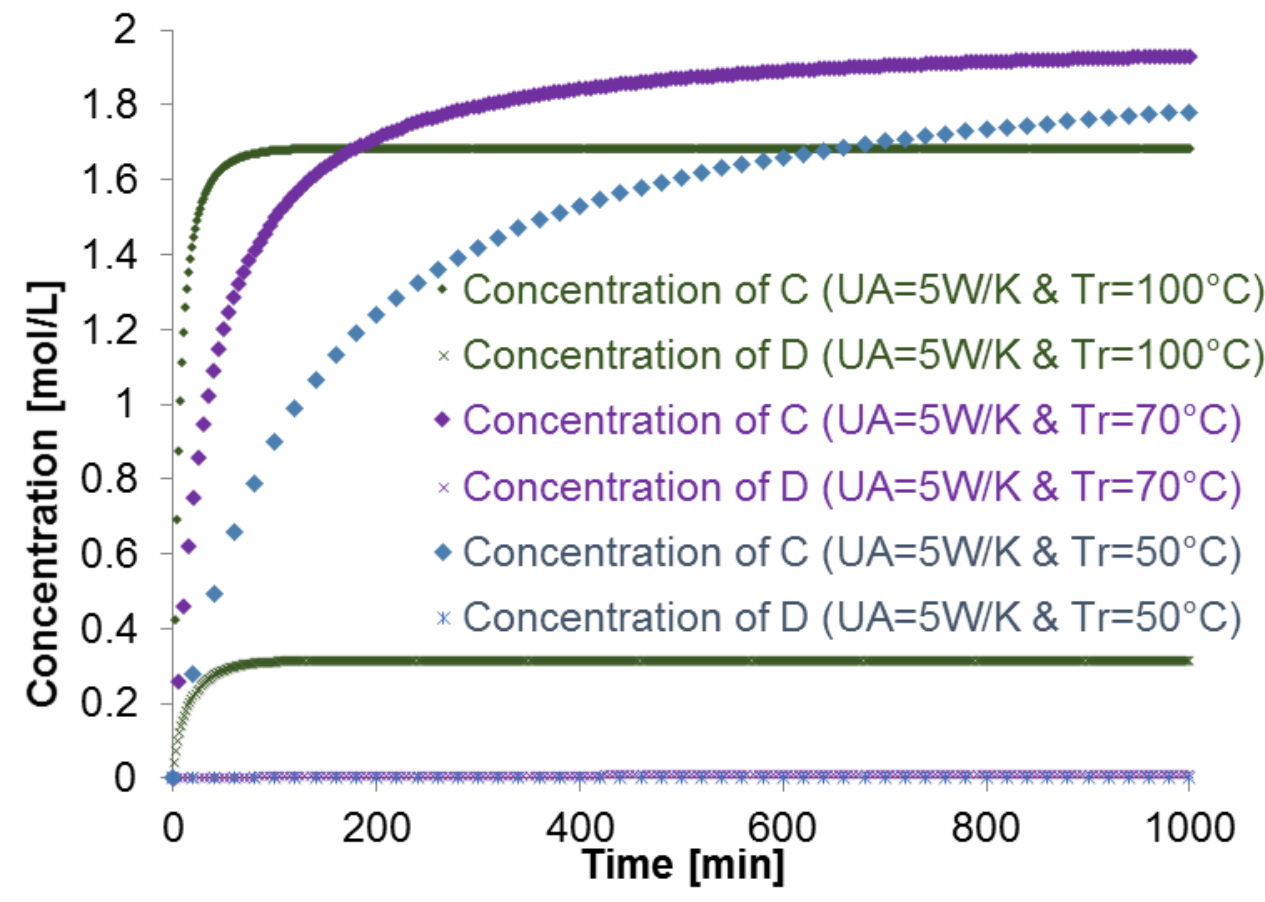

Fig. 6. Effect of reaction temperature on the concentration of compound C and D. 


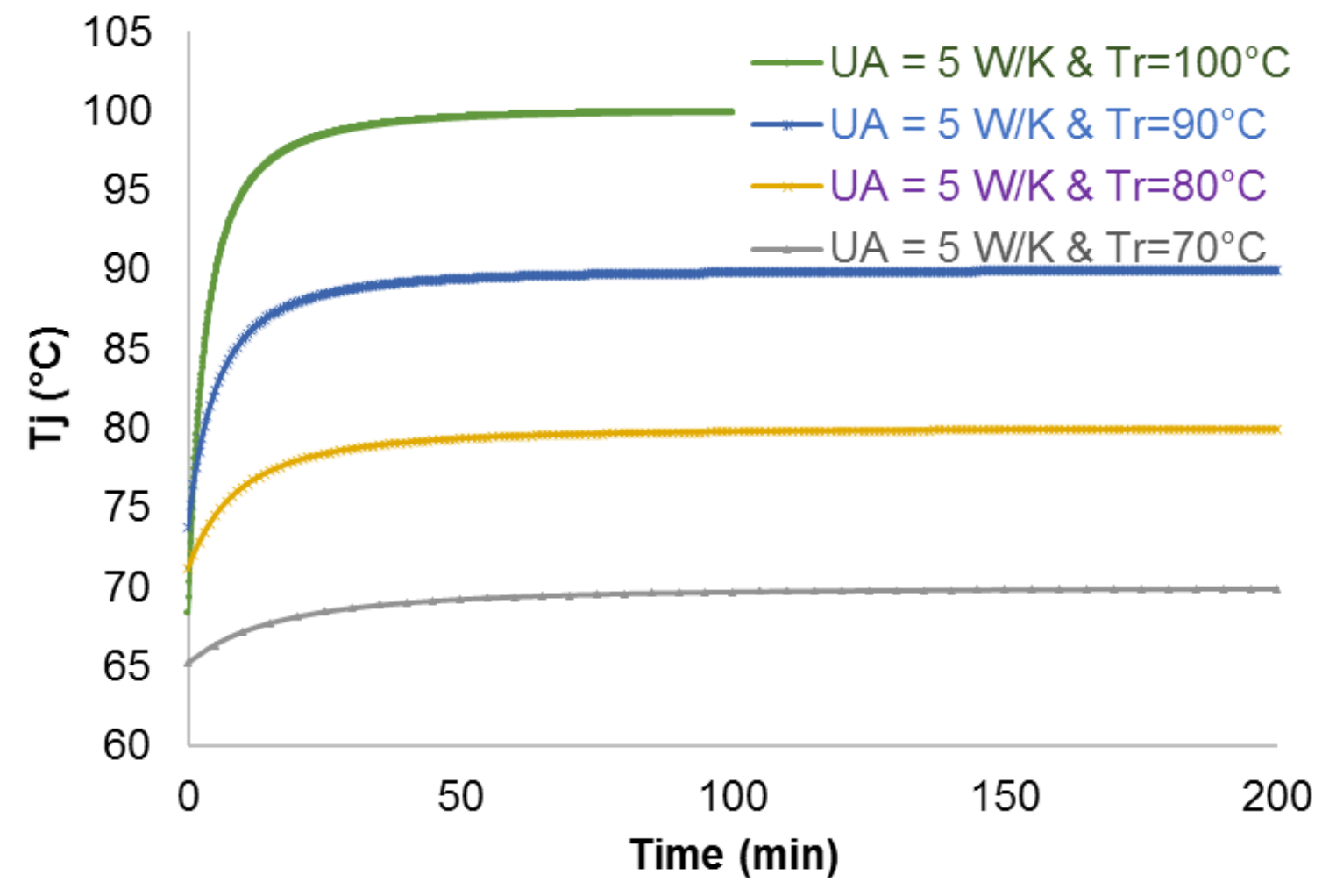

Fig. 7. Effect of reaction temperature on jacket temperature under isothermal conditions. 


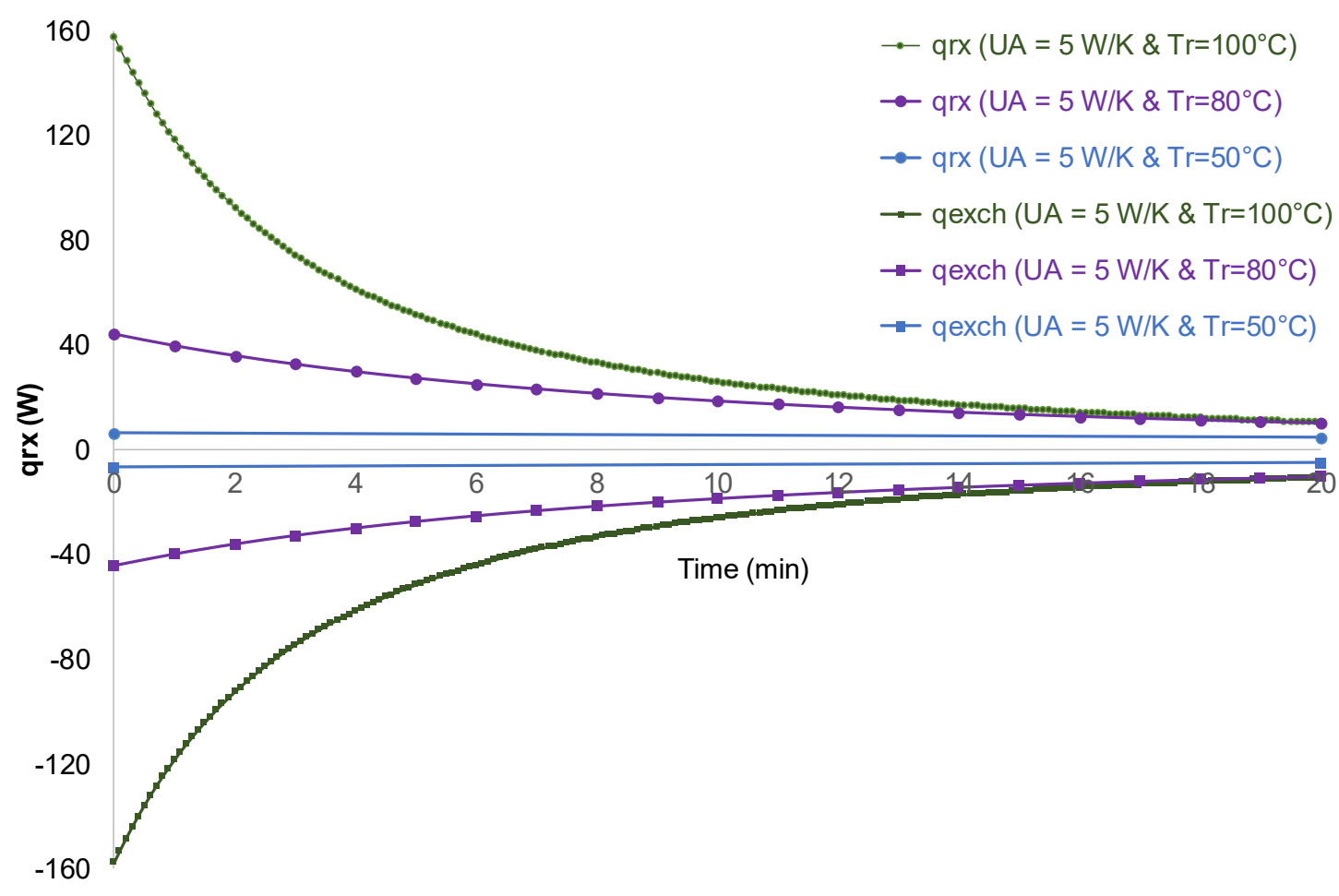

Fig. 8. Effect of reaction temperature on heat-flow rate under isothermal conditions. 


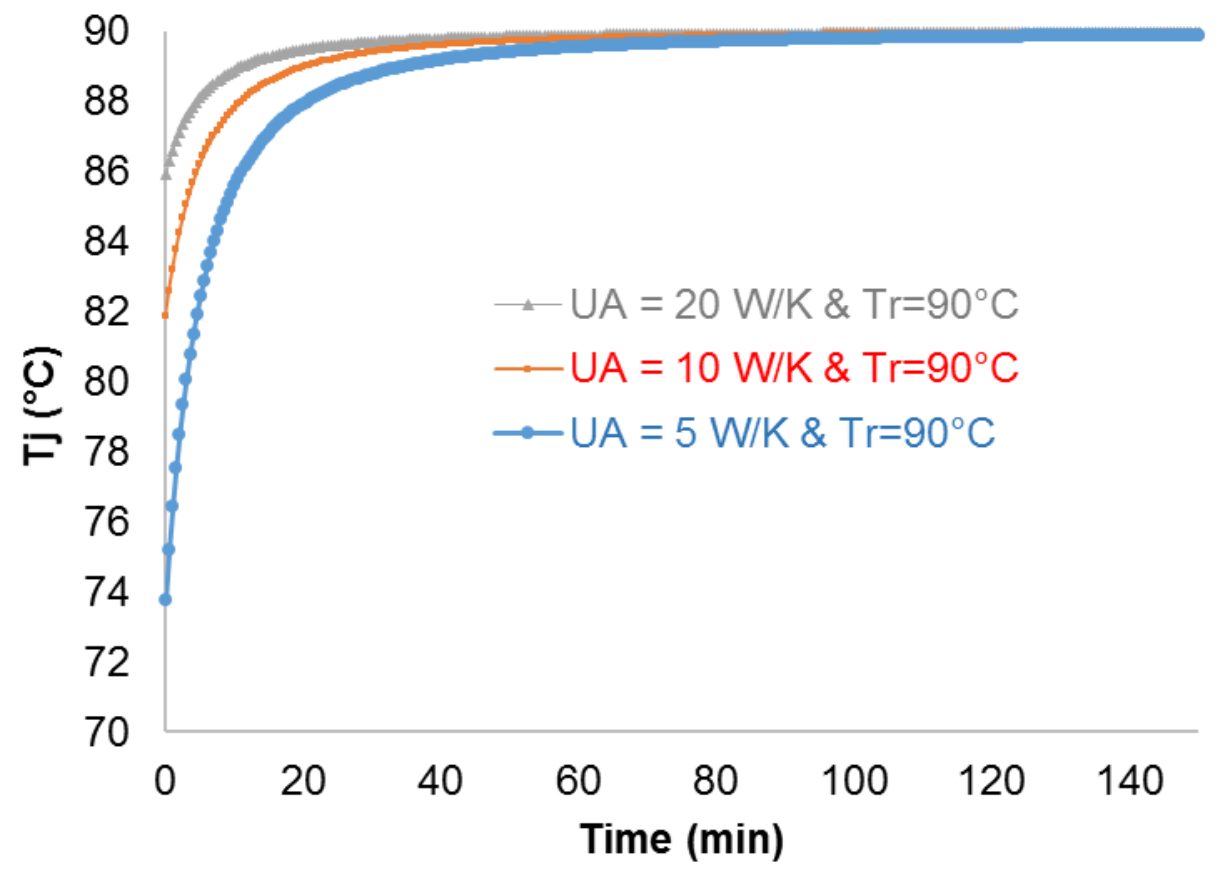

Fig. 9. Effect of UA on the jacket temperature under isothermal condition with $\mathrm{Tj}=90{ }^{\circ} \mathrm{C}$. 


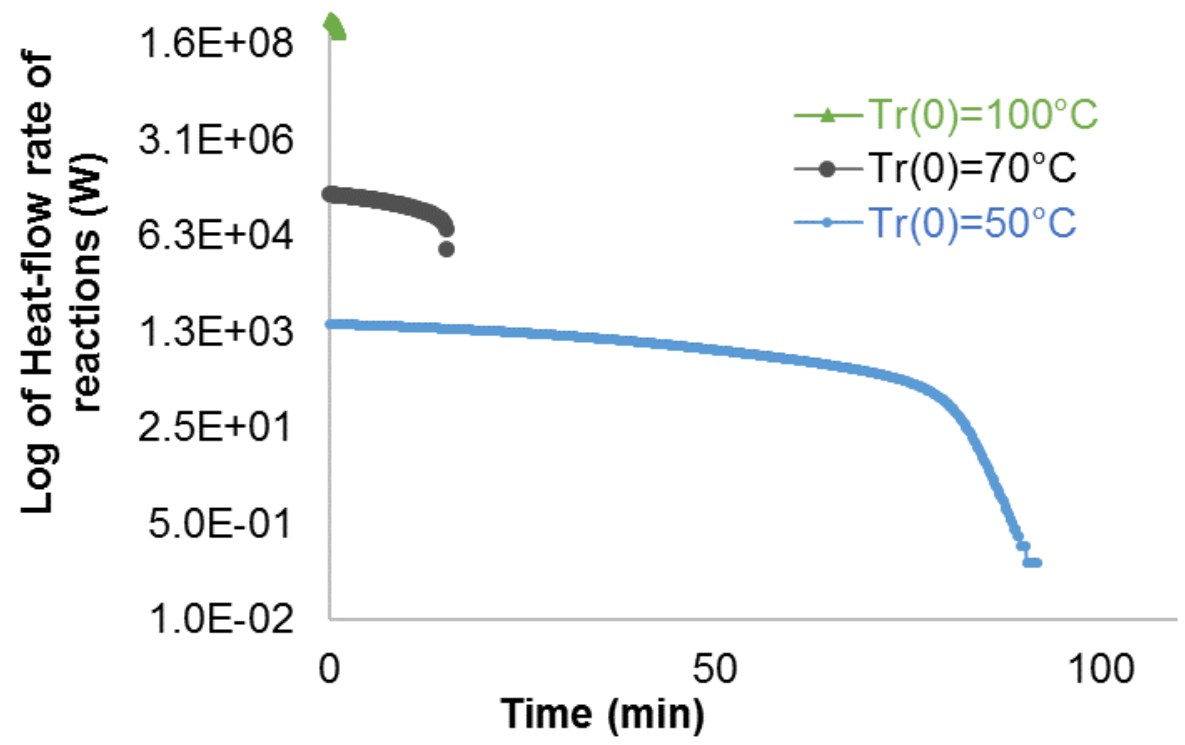

Fig. 10. Logarithm of heat-flow rate of reactions evolution at different initial reaction temperature. 


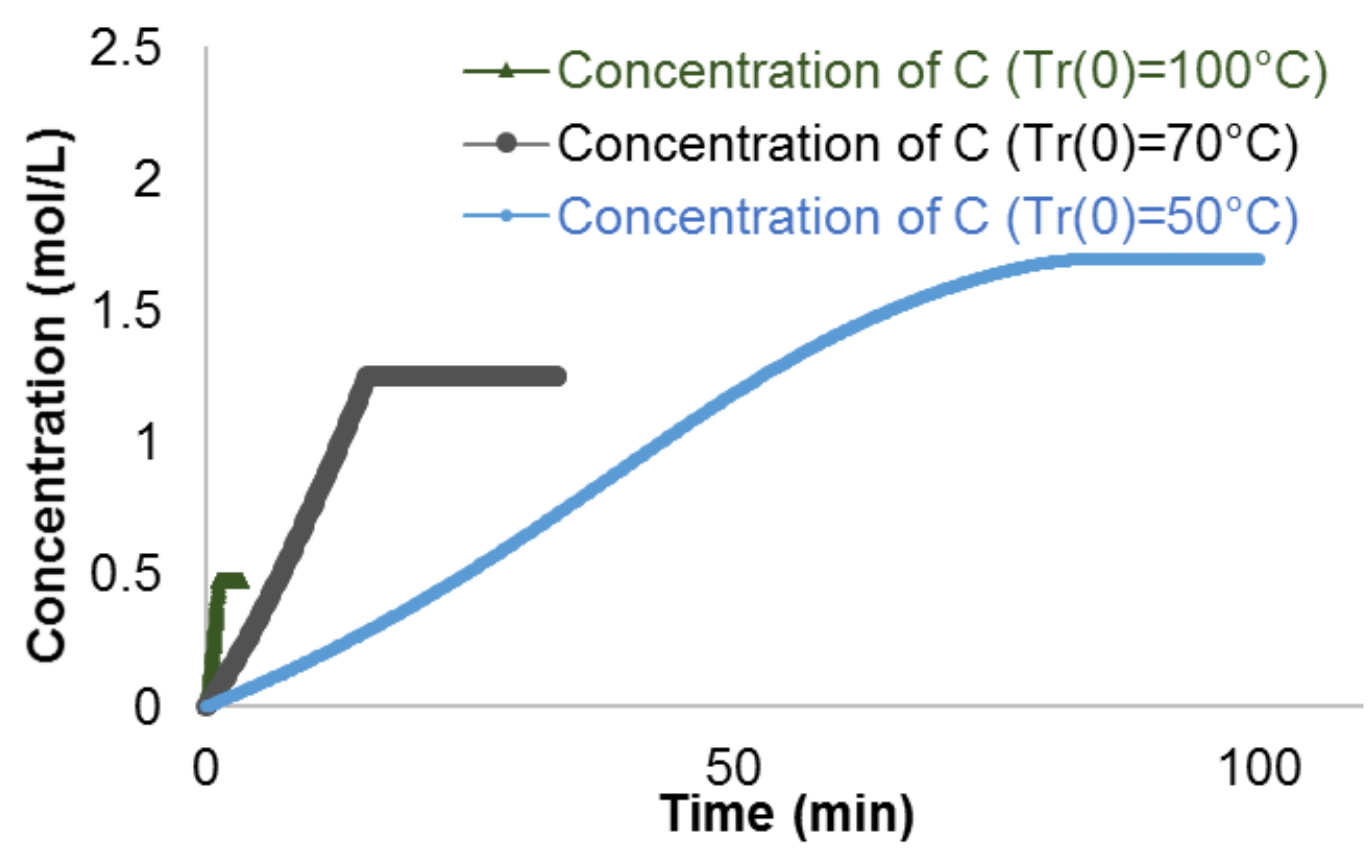

Fig. 11-A. Evolution of the concentration of $\mathrm{C}$ with different initial reaction temperatures. 


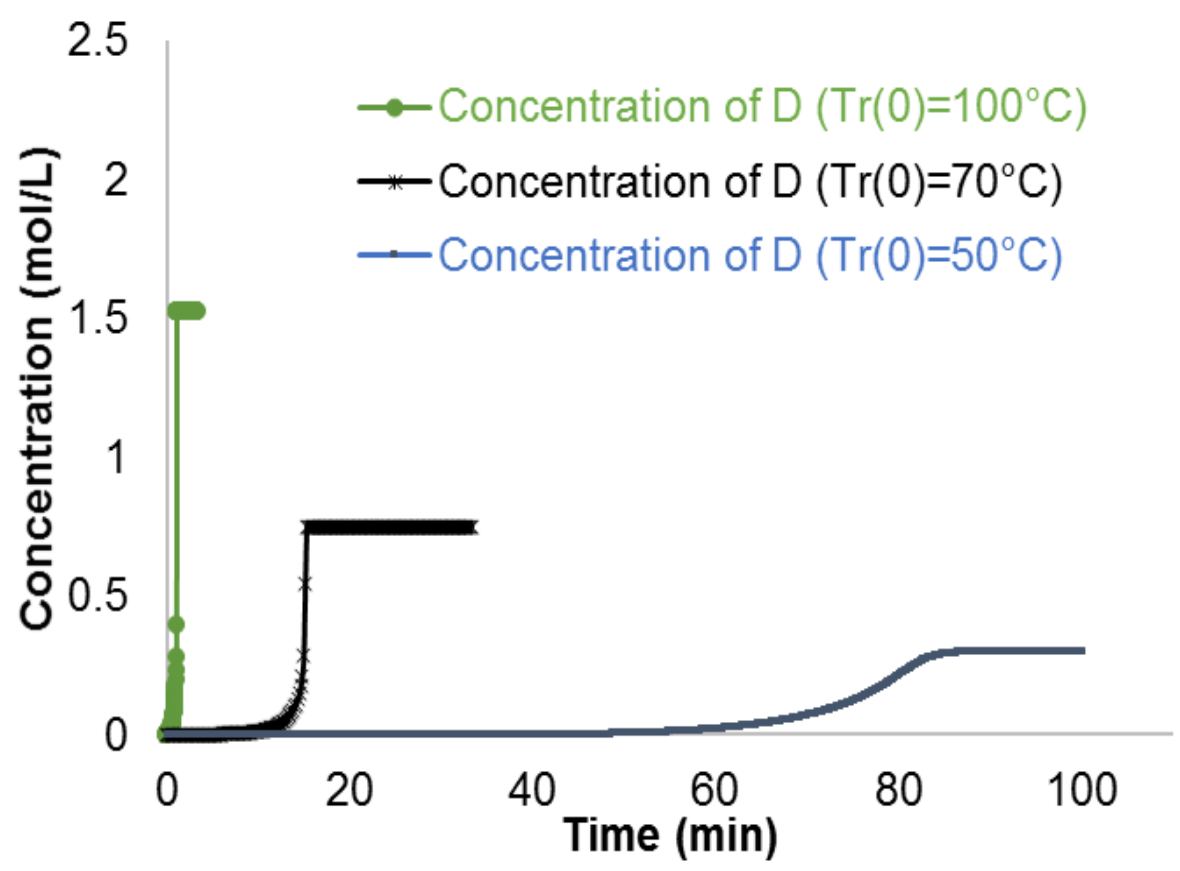

Fig. 11-B. Evolution of the concentration of $\mathrm{D}$ with different initial reaction temperature. 


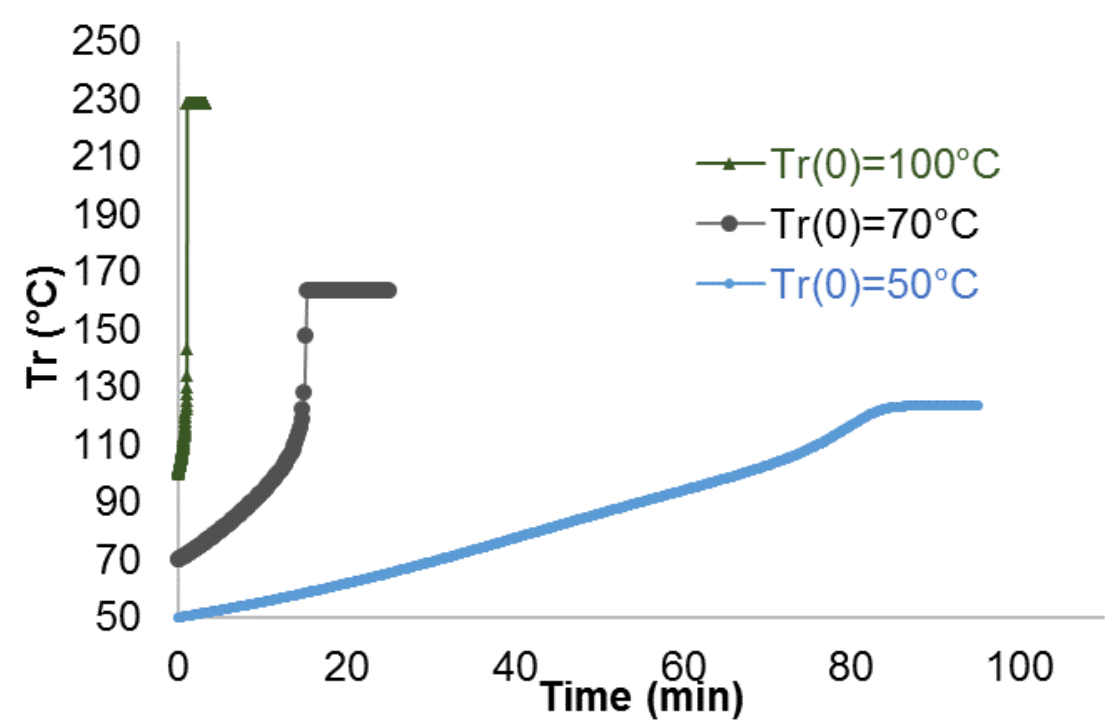

Fig. 12. Reaction temperature evolution with different initial reaction temperatures. 


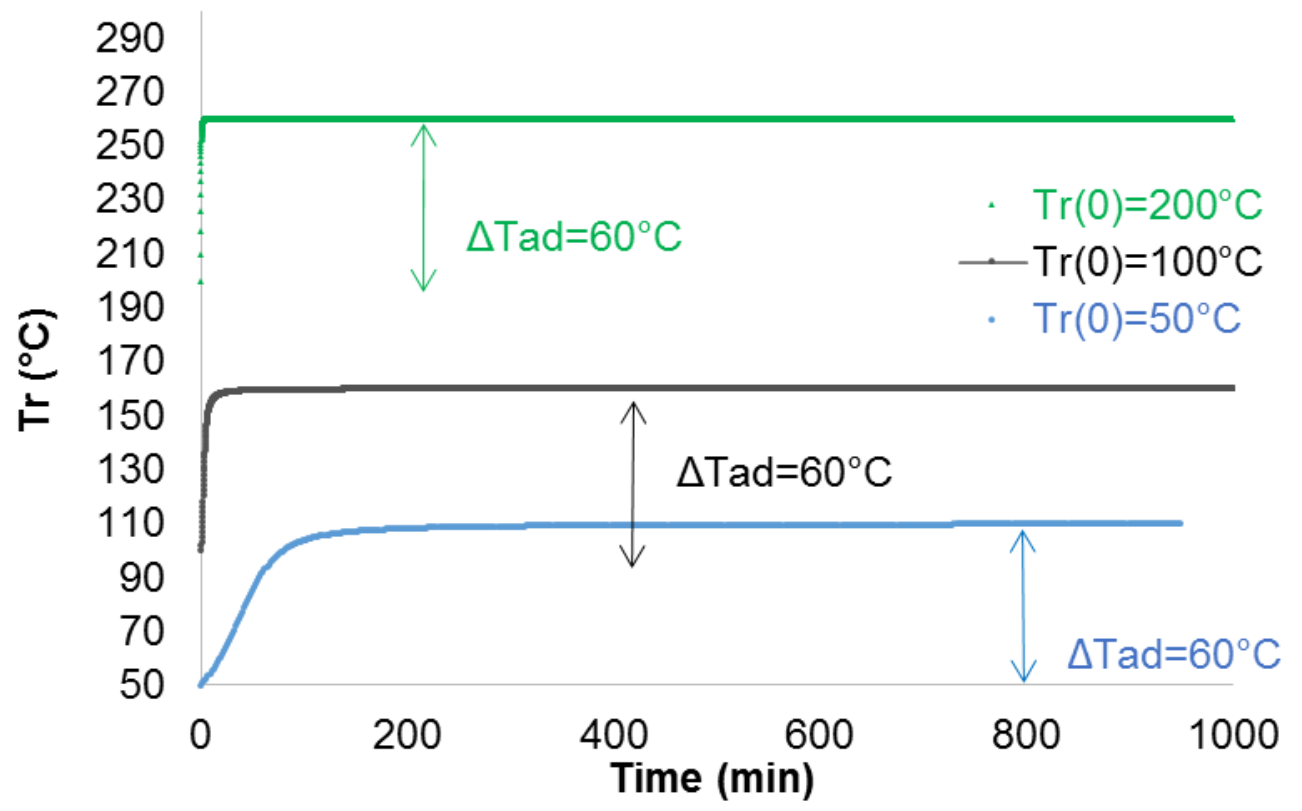

Fig. 13. Evolution of temperature in case of neglecting the second reaction. 
Isothermal mode at $90^{\circ} \mathrm{C}$

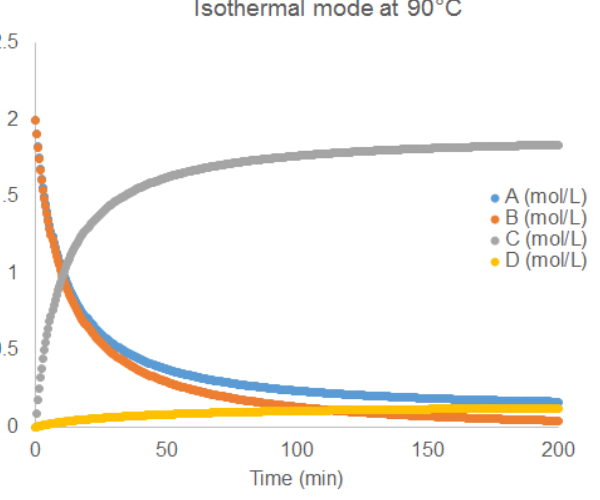

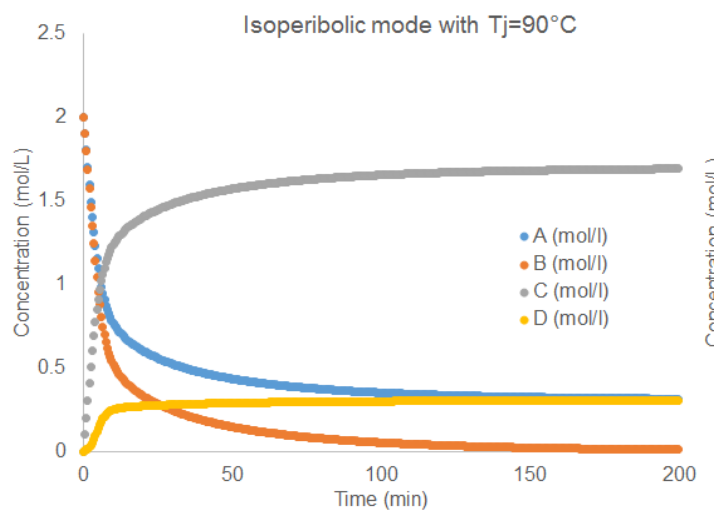

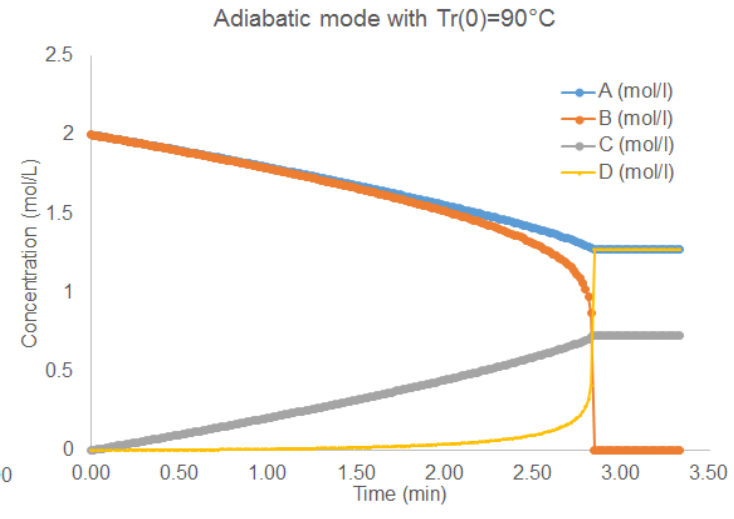

Fig. 14. Evolution of concentration for the three modes. 

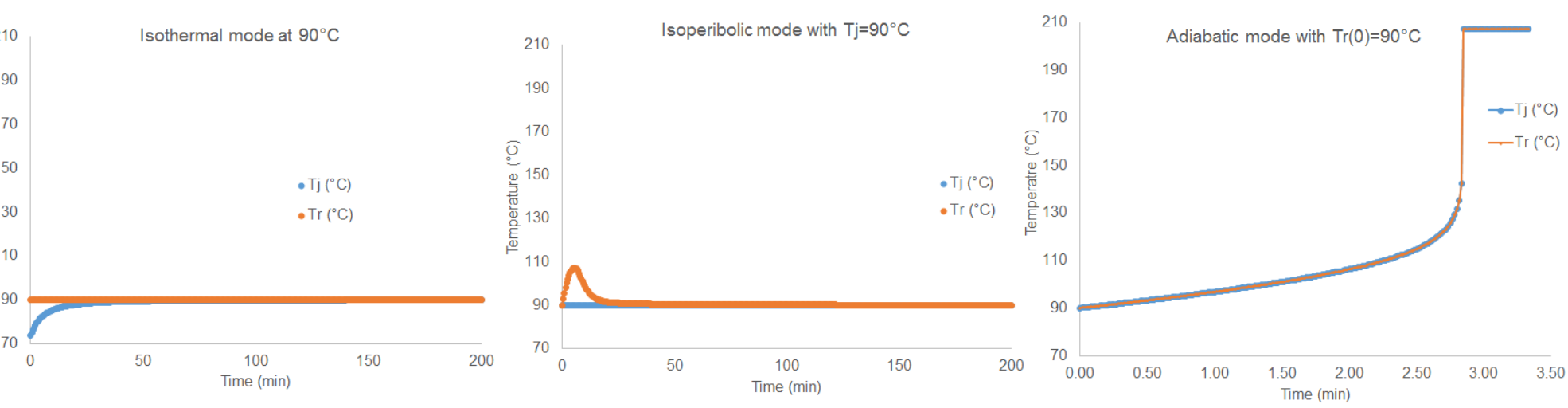

Fig. 15. Evolution of temperature for the three modes. 


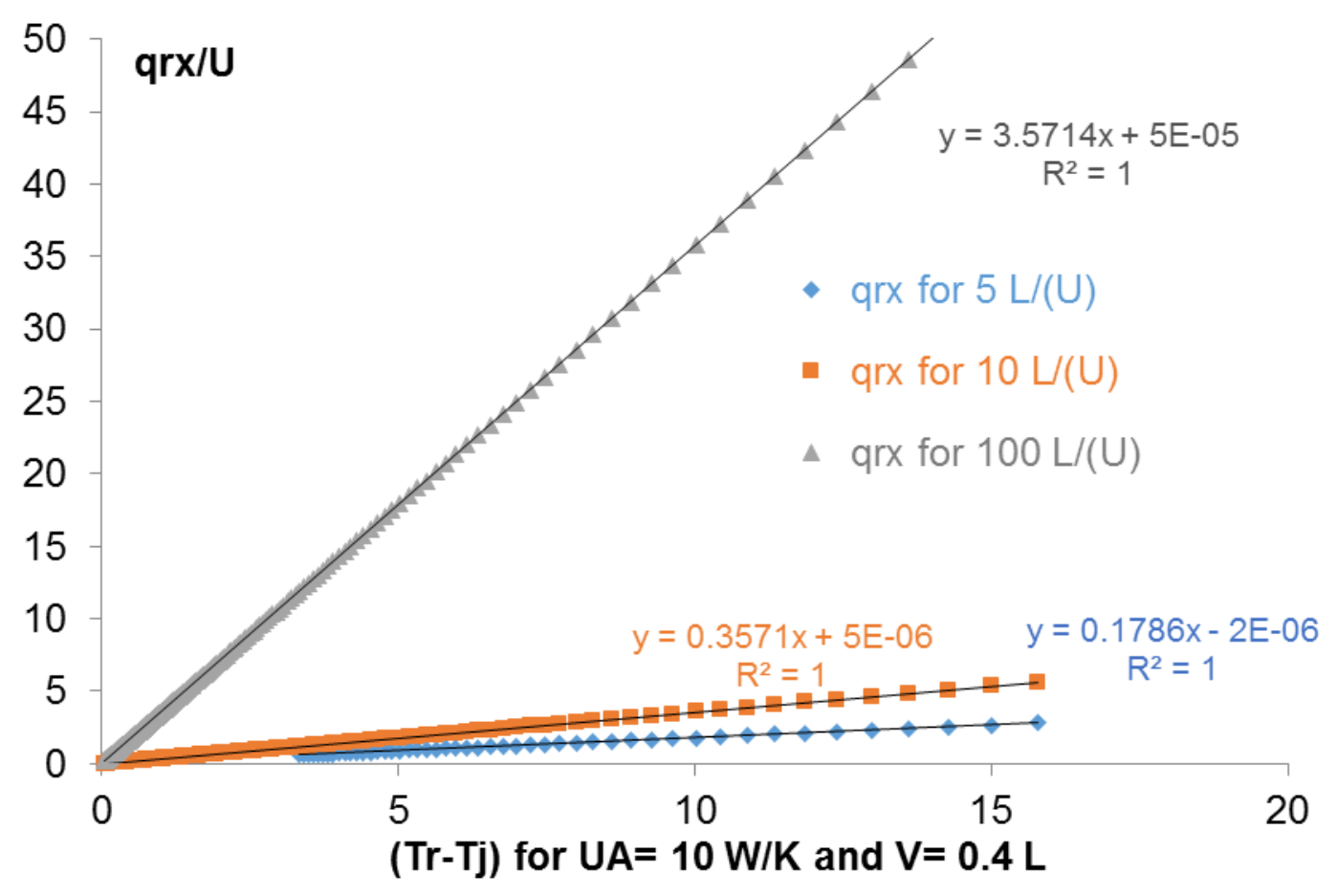

Fig. 16. Determination of the surface area. 


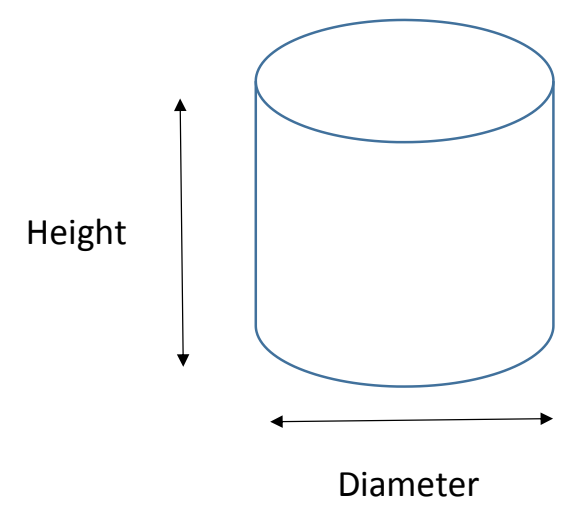

Fig. 17. Reactor dimension. 


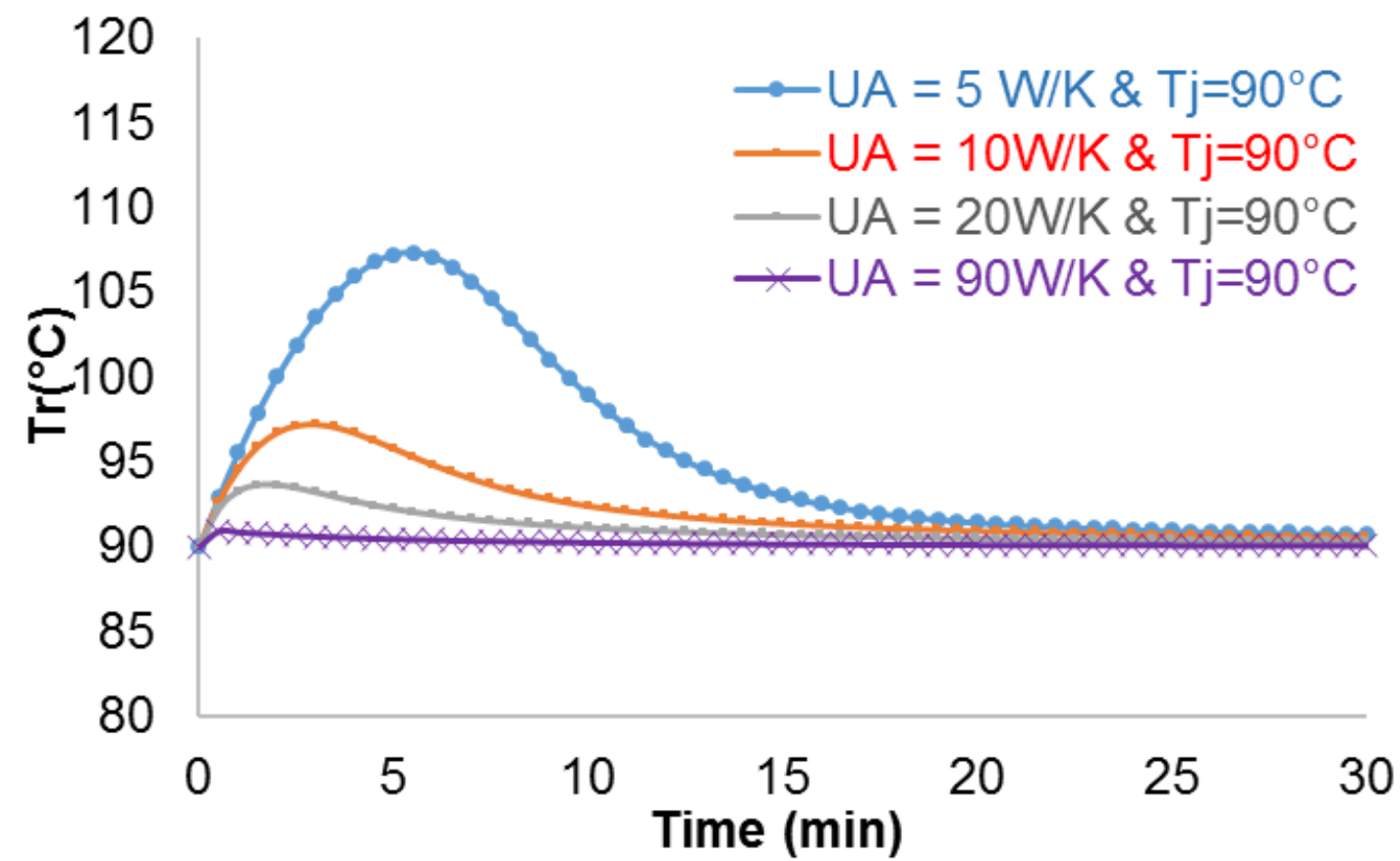

Fig. 18. Influence of UA on reaction temperature under isoperibolic mode with $\mathrm{Tj}=90{ }^{\circ} \mathrm{C}$. 


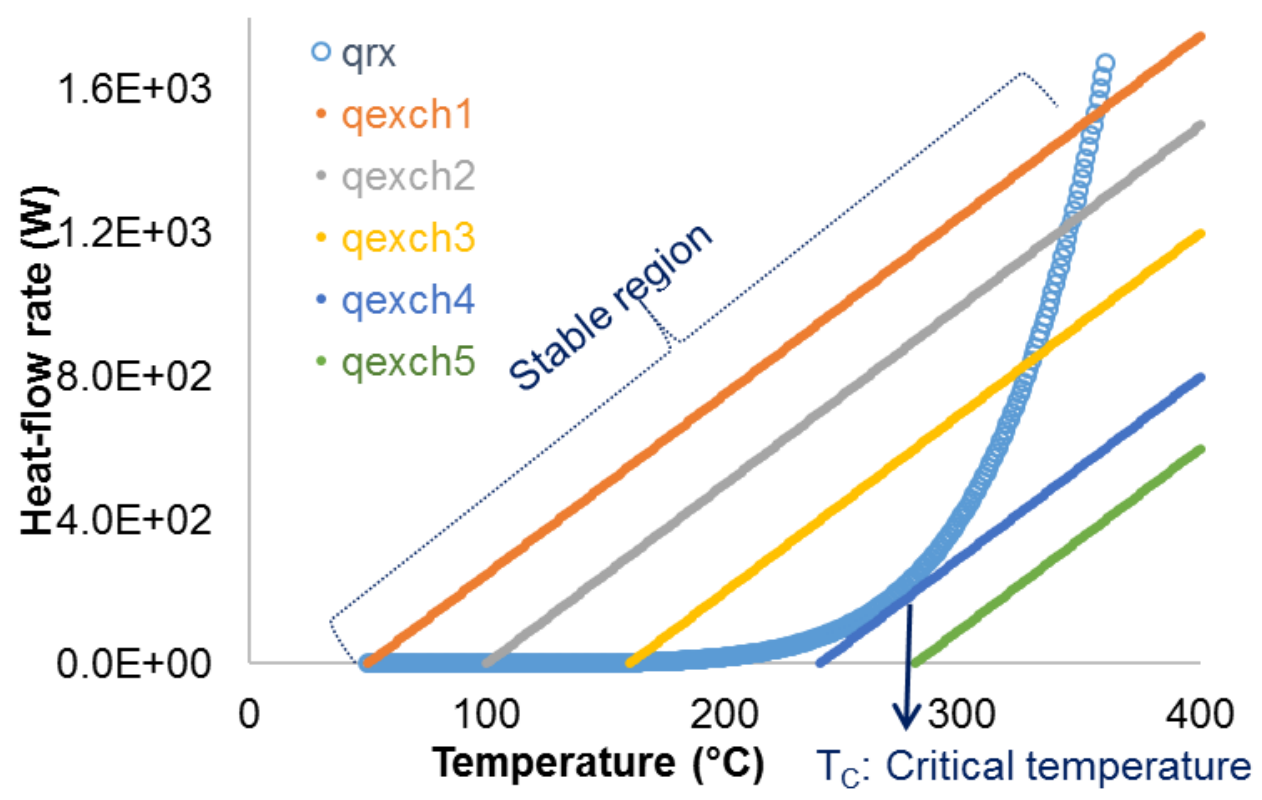

Fig. 19. Semenov curves. 


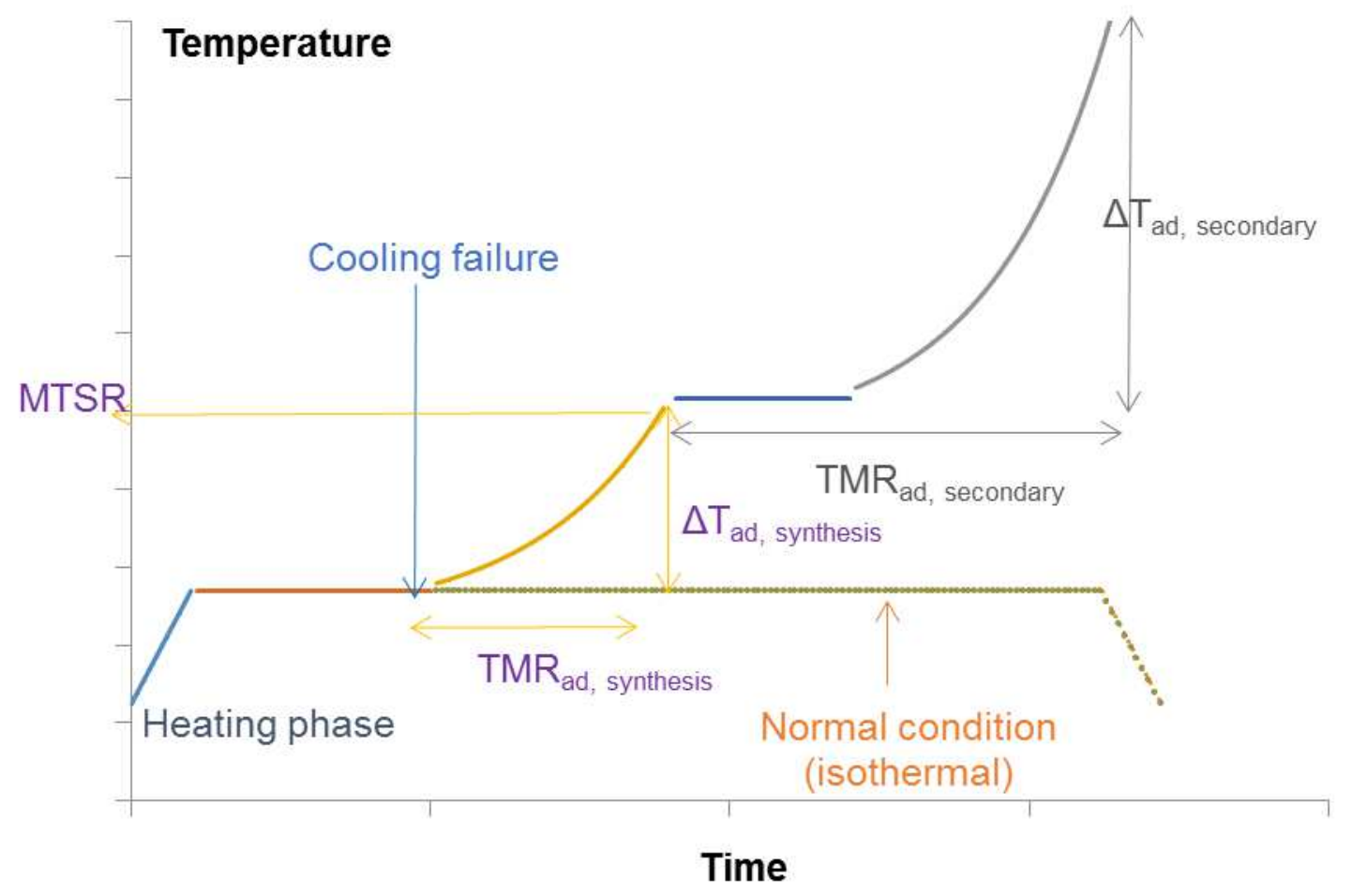

Fig. 20. Cooling failure scenario for an exothermic reaction system in a batch reactor. 


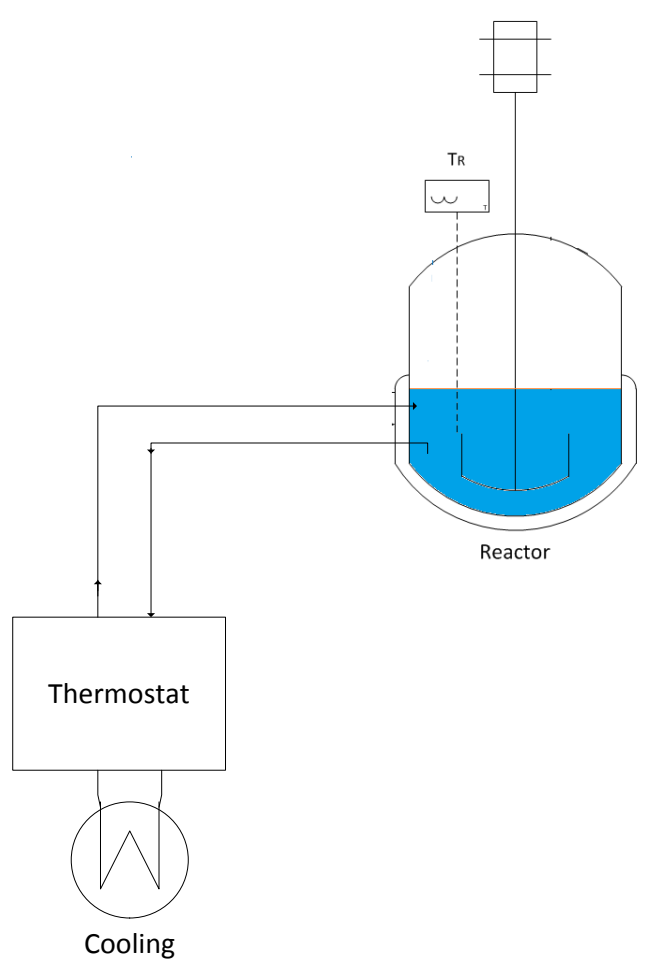

Fig. 21. Reactor system. 


\section{Supporting information}

\section{S1: Energy balance in a chemical reactor}

In a chemical reactor, internal energy is the most important contribution in the energy balance. Potential and kinetic energy are negligible. One can derive eq. (1)

$$
\frac{d U}{d t}=\mathrm{m}_{0} \cdot(\hat{U})_{0}-\mathrm{m}_{1} \cdot(\hat{U})_{1}+\dot{Q}+\mathrm{m}_{0} \cdot \frac{\mathrm{P}_{0}}{\rho_{0}}-\mathrm{m}_{1} \cdot \frac{\mathrm{P}_{1}}{\rho_{1}}+\dot{W}_{S}+\dot{W}_{b}
$$

where, $\dot{W}_{s}$, the shaft work being done by stirrers, compressors, etc.; $\dot{W}_{b}$, the work done when moving the system boundary; $\hat{U}$ is the internal energy per mass; $\mathrm{m}_{0}$ and $\mathrm{m}_{1}$ the mass entering and leaving the chemical reactor; $\mathrm{P}_{0}$ and $\mathrm{P}_{1}$ the pressure at the inlet and outlet; $\rho_{0}$ and $\rho_{1}$ are the density at the inlet and outlet.

where $\dot{Q}$ is the heat-flow rates exchanged with the surroundings.

One should remember that $\mathrm{H}=\mathrm{U}+\mathrm{PV}$ or by per unit mass, $\hat{H}=\hat{U}+\frac{P}{V}$. Thus, eq. (1) becomes:

$$
\begin{aligned}
\frac{d U}{d t} & =\mathrm{m}_{0} \cdot(\hat{H})_{0}-\mathrm{m}_{1} \cdot(\hat{H})_{1}+\dot{Q}+\dot{W}_{S}+\dot{W}_{b} \\
& =(H)_{0}-(H)_{1}+\dot{Q}+\dot{W}_{S}+\dot{W}_{b} \\
& =(H)_{\text {inlet }}-(H)_{\text {outlet }}+\dot{Q}+\dot{W}_{S}+\dot{W}_{b} \\
\frac{\mathrm{dU}}{\mathrm{dt}} & =\dot{\mathrm{H}}_{\text {inlet }}-\dot{\mathrm{H}}_{\text {oulet }}+\dot{\mathrm{Q}}+\dot{\mathrm{W}}_{\text {shaft }}+\dot{\mathrm{W}}_{\text {boundary }}
\end{aligned}
$$

The boundary work can be expressed as $-P \cdot \frac{d V_{R}}{d t}$, thus eq. (3) can be expressed as

$$
\frac{d U}{d t}=(\dot{\mathrm{H}})_{\text {inlet }}-(\dot{\mathrm{H}})_{\text {outlet }}+\dot{Q}+\dot{W}_{S}-P \cdot \frac{d V_{R}}{d t}
$$

One should remember the definition of the enthalpy function

$$
\begin{aligned}
& H=U+P V_{R} \\
& \Leftrightarrow d H=d U+P \cdot d V_{R}+V_{R} \cdot d P \\
& \Leftrightarrow \frac{d H}{d t}=\frac{d U}{d t}+P \cdot \frac{d V_{R}}{d t}+V_{R} \cdot \frac{d P}{d t} \\
& \Leftrightarrow \frac{d U}{d t}=\frac{d H}{d t}-P \cdot \frac{d V_{R}}{d t}-V_{R} \cdot \frac{d P}{d t}
\end{aligned}
$$


Thus, eq.(4) and eq.(5) becomes

$$
\frac{\mathrm{dH}}{\mathrm{dt}}-\mathrm{V}_{\mathrm{R}} \cdot \frac{\mathrm{dP}}{\mathrm{dt}}=\dot{\mathrm{H}}_{\text {inlet }}-\dot{\mathrm{H}}_{\text {outlet }}+\dot{\mathrm{Q}}+\dot{\mathrm{W}}_{\mathrm{S}}
$$

Enthalpy is function of temperature, pressure and number of moles and can be expressed as

$$
\mathrm{dH}=\left(\frac{\partial \mathrm{H}}{\partial \mathrm{T}}\right)_{\mathrm{P}, \mathrm{n}_{\mathrm{j}}} \mathrm{dT}+\left(\frac{\partial \mathrm{H}}{\partial \mathrm{P}}\right)_{\mathrm{T}, \mathrm{n}_{\mathrm{j}}} \mathrm{dP}+\sum_{\mathrm{j}}\left(\frac{\partial \mathrm{H}}{\partial \mathrm{n}_{\mathrm{j}}}\right)_{\mathrm{T}, \mathrm{P}, \mathrm{n}_{\mathrm{k}}} \mathrm{dn_{j }}
$$

where,

$$
\begin{aligned}
& \left(\frac{\partial H}{\partial T}\right)_{P, n_{j}}=\mathrm{C}_{\mathrm{P}}=\mathrm{V}_{\mathrm{R}} \cdot \rho_{\mathrm{R}} \cdot \hat{\mathrm{C}}_{\mathrm{P}} \\
& \left(\frac{\partial \mathrm{H}}{\partial \mathrm{P}}\right)_{\mathrm{T}, \mathrm{n}_{\mathrm{j}}}=\mathrm{V}-\mathrm{T}\left(\frac{\partial \mathrm{V}}{\partial \mathrm{T}}\right)_{\mathrm{P}, \mathrm{n}_{\mathrm{j}}}=\mathrm{V} \cdot(1-\alpha \mathrm{T}) \\
& \left(\frac{\partial \mathrm{H}}{\partial \mathrm{n}_{\mathrm{j}}}\right)_{\mathrm{T}, \mathrm{P}, \mathrm{n}_{\mathrm{k}}}=\overline{\mathrm{H}}_{\mathrm{j}}
\end{aligned}
$$

Thus, eq. (7) becomes

$$
\mathrm{dH}=\mathrm{V}_{\mathrm{R}} \cdot \rho_{\mathrm{R}} \cdot \hat{\mathrm{C}}_{\mathrm{P}} \mathrm{dT}+(1-\alpha \mathrm{T}) \cdot \mathrm{V}_{\mathrm{R}} \cdot \mathrm{dP}+\sum_{\mathrm{j}} \overline{\mathrm{H}}_{\mathrm{j}} \mathrm{dn}_{\mathrm{j}}
$$

Addition of Eq. (6) and (11) leads to

$$
\begin{aligned}
& \mathrm{V}_{\mathrm{R}} \cdot \rho_{\mathrm{R}} \cdot \hat{\mathrm{C}}_{\mathrm{P}} \cdot \frac{\mathrm{dT}}{\mathrm{dt}}-\alpha \cdot \mathrm{T} \cdot \mathrm{V}_{\mathrm{R}} \cdot \frac{\mathrm{dP}}{\mathrm{dt}}+\sum_{\mathrm{j}} \overline{\mathrm{H}}_{\mathrm{j}} \frac{\mathrm{dn}_{\mathrm{j}}}{\mathrm{dt}}=\dot{\mathrm{H}}_{\text {inlet }}-\dot{\mathrm{H}}_{\text {outlet }}+\dot{\mathrm{Q}}+\dot{\mathrm{W}}_{\mathrm{S}} \\
& \left(\mathrm{V}_{\mathrm{R}} \cdot \rho_{\mathrm{R}} \cdot \hat{\mathrm{C}}_{\mathrm{P}}+\mathrm{m}_{\text {insert }} \cdot \hat{\mathrm{C}}_{\mathrm{P}_{\text {insert }}}\right) \frac{\mathrm{dT}_{\mathrm{R}}}{\mathrm{dt}}-\alpha \cdot \mathrm{T} \cdot \mathrm{V}_{\mathrm{R}} \cdot \frac{\mathrm{dP}}{\mathrm{dt}}+\sum_{\mathrm{j}} \overline{\mathrm{H}}_{\mathrm{j}} \frac{\mathrm{dn}_{\mathrm{j}}}{\mathrm{dt}}=\dot{\mathrm{H}}_{\text {inlet }}-\dot{\mathrm{H}}_{\text {outlet }}+\dot{\mathrm{Q}}+\dot{\mathrm{W}}_{\mathrm{S}}
\end{aligned}
$$




\section{S2: Effect of pressure on the energy balance}

The energy balance for a batch reactor can be defined as

$\left(\mathrm{V}_{\mathrm{R}} \cdot \rho_{\mathrm{R}} \cdot \hat{\mathrm{C}}_{\mathrm{P}}+\mathrm{m}_{\text {insert }} \cdot \hat{\mathrm{C}}_{\mathrm{P}_{\text {insert }}}\right) \frac{\mathrm{dT}_{\mathrm{R}}}{\mathrm{dt}}-\alpha \cdot \mathrm{T}_{\mathrm{R}} \cdot \mathrm{V}_{\mathrm{R}} \cdot \frac{\mathrm{dP}_{\mathrm{R}}}{\mathrm{dt}}+\sum_{i=1}^{\mathrm{n}_{\mathrm{R}}} \Delta \mathrm{H}_{\mathrm{Ri}} \cdot \mathrm{R}_{\mathrm{i}} \cdot \mathrm{V}_{\mathrm{R}}=\dot{\mathrm{Q}}+\dot{\mathrm{W}}_{\mathrm{S}}$

If the pressure is not constant, then one should express the variation of pressure as

$$
\mathrm{dP}=\left(\frac{\partial \mathrm{P}}{\partial \mathrm{T}}\right)_{\mathrm{V}, \mathrm{n}_{\mathrm{j}}} . \mathrm{dT}+\left(\frac{\partial \mathrm{P}}{\partial \mathrm{V}}\right)_{\mathrm{T}, \mathrm{n}_{\mathrm{j}}} \cdot \mathrm{dV}+\sum_{\mathrm{j}}\left(\frac{\partial \mathrm{P}}{\partial \mathrm{n}_{\mathrm{j}}}\right)_{\mathrm{T}, \mathrm{V}, \mathrm{n}_{\mathrm{k}}} . \mathrm{dn}_{\mathrm{j}}
$$

In the case of a batch reactor, the reaction volume is constant then $\mathrm{dV}=0$;

$$
\frac{\mathrm{dP}}{\mathrm{dt}}=\left(\frac{\partial \mathrm{P}}{\partial \mathrm{T}}\right)_{\mathrm{V}, \mathrm{n}_{\mathrm{j}}} \cdot \frac{\mathrm{dT}}{\mathrm{dt}}+\sum_{\mathrm{j}}\left(\frac{\partial \mathrm{P}}{\partial \mathrm{n}_{\mathrm{j}}}\right)_{\mathrm{T}, \mathrm{V}, \mathrm{n}_{\mathrm{k}}} \cdot \frac{\mathrm{dn}_{\mathrm{j}}}{\mathrm{dt}}
$$

Then, eq. (1) becomes

$$
\begin{aligned}
& \left(\mathrm{V}_{\mathrm{R}} \cdot \rho \cdot \hat{\mathrm{C}}_{\mathrm{P}}+\mathrm{m}_{\text {inserts }} \cdot \hat{\mathrm{C}}_{\mathrm{P}_{\mathrm{insert}}}\right) \cdot \frac{\mathrm{dT}_{\mathrm{R}}}{\mathrm{dt}}-\alpha \cdot \mathrm{T}_{\mathrm{R}} \cdot \mathrm{V}_{\mathrm{R}} \cdot \frac{\mathrm{dP}_{\mathrm{R}}}{\mathrm{dt}}+\sum_{\mathrm{i}=1}^{\mathrm{n}_{\mathrm{R}}} \Delta \mathrm{H}_{\mathrm{Ri}} \cdot \mathrm{R}_{\mathrm{i}} \cdot \mathrm{V}_{\mathrm{R}}=\dot{\mathrm{Q}}+\dot{\mathrm{W}}_{\mathrm{S}} \\
& \Leftrightarrow\left(\mathrm{V}_{\mathrm{R}} \cdot \rho \cdot \hat{\mathrm{C}}_{\mathrm{P}}+\mathrm{m}_{\text {inserts }} \cdot \hat{\mathrm{C}}_{\mathrm{P}_{\text {inserts }}}\right) \frac{\mathrm{dT}_{\mathrm{R}}}{\mathrm{dt}}-\alpha \cdot \mathrm{T}_{\mathrm{R}} \cdot \mathrm{V}_{\mathrm{R}} \cdot\left(\left(\frac{\partial \mathrm{P}_{\mathrm{R}}}{\partial \mathrm{T}_{\mathrm{R}}}\right)_{\mathrm{V}, \mathrm{n}_{\mathrm{j}}} \cdot \frac{\mathrm{dT}_{\mathrm{R}}}{\mathrm{dt}}+\sum_{\mathrm{j}}\left(\frac{\partial \mathrm{P}_{\mathrm{R}}}{\partial \mathrm{n}_{\mathrm{j}}}\right)_{\mathrm{T}, \mathrm{V}, \mathrm{n}_{\mathrm{k}}} \cdot \frac{\mathrm{dn}_{\mathrm{j}}}{\mathrm{dt}}\right)+\sum_{\mathrm{i}=1}^{\mathrm{n}_{\mathrm{R}}} \Delta \mathrm{H}_{\mathrm{Ri}} \cdot \mathrm{R}_{\mathrm{i}} \cdot \mathrm{V}_{\mathrm{R}}=\dot{\mathrm{Q}}+\dot{\mathrm{W}}_{\mathrm{S}} \\
& \Leftrightarrow\left(\mathrm{V}_{\mathrm{R}} \cdot \rho \cdot \hat{\mathrm{C}}_{\mathrm{P}}+\mathrm{m}_{\text {inserts }} \cdot \hat{\mathrm{C}}_{\mathrm{P}_{\text {inserts }}}-\alpha \cdot \mathrm{T}_{\mathrm{R}} \cdot \mathrm{V}_{\mathrm{R}} \cdot\left(\frac{\partial \mathrm{P}_{\mathrm{R}}}{\partial \mathrm{T}_{\mathrm{R}}}\right)_{\mathrm{V}, \mathrm{n}_{\mathrm{j}}}\right) \cdot \frac{\mathrm{dT}_{\mathrm{R}}}{\mathrm{dt}}-\alpha \cdot \mathrm{T}_{\mathrm{R}} \cdot \mathrm{V}_{\mathrm{R}} \cdot \sum_{\mathrm{j}}\left(\frac{\partial \mathrm{P}_{\mathrm{R}}}{\partial \mathrm{n}_{\mathrm{j}}}\right)_{\mathrm{T}, \mathrm{V}, \mathrm{n}_{\mathrm{k}}} \cdot \frac{\mathrm{dn}_{\mathrm{j}}}{\mathrm{dt}}+\sum_{\mathrm{i}=1}^{\mathrm{n}_{\mathrm{R}}} \Delta \mathrm{H}_{\mathrm{Ri}} \cdot \mathrm{R}_{\mathrm{i}} \cdot \mathrm{V}_{\mathrm{R}}=\dot{\mathrm{Q}}+\dot{\mathrm{W}}_{\mathrm{S}} \\
& \text { with } \mathrm{V}_{\mathrm{R}} \cdot \rho_{\mathrm{R}} \cdot \hat{\mathrm{C}}_{\mathrm{V}}=\mathrm{V}_{\mathrm{R}} \cdot \rho_{\mathrm{R}} \cdot \hat{\mathrm{C}}_{\mathrm{P}}+\mathrm{m}_{\mathrm{inserts}} \cdot \hat{\mathrm{C}}_{\mathrm{P}_{\mathrm{insert}}}-\alpha \cdot \mathrm{T}_{\mathrm{R}} \cdot \mathrm{V}_{\mathrm{R}} \cdot\left(\frac{\partial \mathrm{P}_{\mathrm{R}}}{\partial \mathrm{T}_{\mathrm{R}}}\right)_{\mathrm{V}, \mathrm{n}_{\mathrm{j}}}
\end{aligned}
$$

If the pressure is constant, then eq. (1) simplified to

$$
\left(\mathrm{V}_{\mathrm{R}} \cdot \rho_{\mathrm{R}} \cdot \hat{\mathrm{C}}_{\mathrm{P}}+\mathrm{m}_{\text {insert }} \cdot \hat{\mathrm{C}}_{\mathrm{P}_{\text {insert }}}\right) \frac{\mathrm{dT}_{\mathrm{R}}}{\mathrm{dt}}+\sum_{i=1}^{\mathrm{n}_{\mathrm{R}}} \Delta \mathrm{H}_{\mathrm{Ri}} \cdot \mathrm{R}_{\mathrm{i}} \cdot \mathrm{V}_{\mathrm{R}}=\dot{\mathrm{Q}}+\dot{\mathrm{W}}_{\mathrm{S}}
$$




\section{S3: Matlab code}

\section{Under isothermal mode}

\section{The code is}

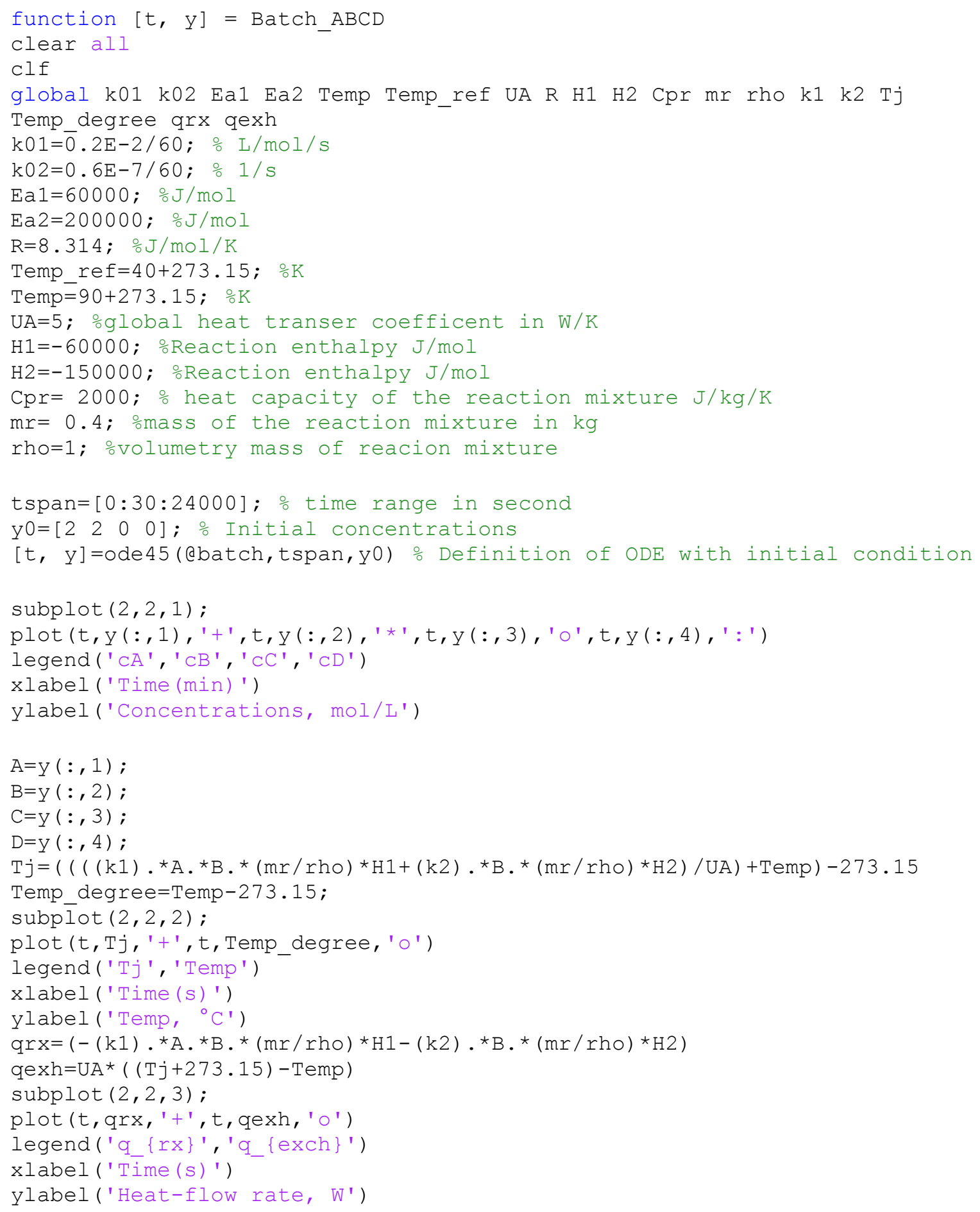


function dydt=batch $(t, y)$

global k01 k02 Ea1 Ea2 Temp Temp_ref UA R H1 H2 Cpr mr rho k1 k2 R1 R2 Tj

$\mathrm{k} 1=\mathrm{k} 01^{*} \exp (-(\mathrm{Ea} 1 / \mathrm{R}) *((1 /$ Temp $)-(1 /$ Temp ref $))) ;$ oModified arrhenius equation

$\mathrm{k} 2=\mathrm{k} 02 * \exp (-(\mathrm{Ea} 2 / \mathrm{R}) *((1 / \mathrm{Temp})-(1 /$ Temp_ref $)))$; oModified arrhenius equation

$\mathrm{R} 1=\mathrm{k} 1{ }^{*} \mathrm{Y}(1){ }^{*} \mathrm{Y}(2)$;

$\mathrm{R} 2=\mathrm{k} 2 * \mathrm{y}(2) ;$

dydt $=[-\mathrm{R} 1 ;-\mathrm{R} 1-\mathrm{R} 2 ;+\mathrm{R} 1 ;+\mathrm{R} 2]$; oWatch out: the order of the different ODE

should coincide with intial condition

XXXXXXXXXXXXXXXXXXXXXXXXXXXXXXXXXXXXXXXXXXXXXXXXXXXXXXXXXXXXXX

The instructor should explain briefly the structure of the code to the students. They should be aware of the different aspect of the code. He should also explain how to take the different results from the Matlab environment.

A modified Arrhenius equation can be introduced as:

$\mathrm{k}_{\mathrm{j}, \mathrm{T}}=\mathrm{k}_{\mathrm{j}, \mathrm{T}_{\mathrm{Ref}}} \cdot \exp \left(\frac{-\mathrm{Ea}_{\mathrm{j}}}{\mathrm{R}} \cdot\left(\frac{1}{\mathrm{~T}}-\frac{1}{\mathrm{~T}_{\mathrm{Ref}}}\right)\right)$

If Matlab is used, then the instructor should insist that the method was numerically solved by using a Runge-Katta algorithm. The instructor should emphasis on the fact that this solver might not be correct in case of stiff equations. 


\section{Under adiabatic mode}

\section{The code is}

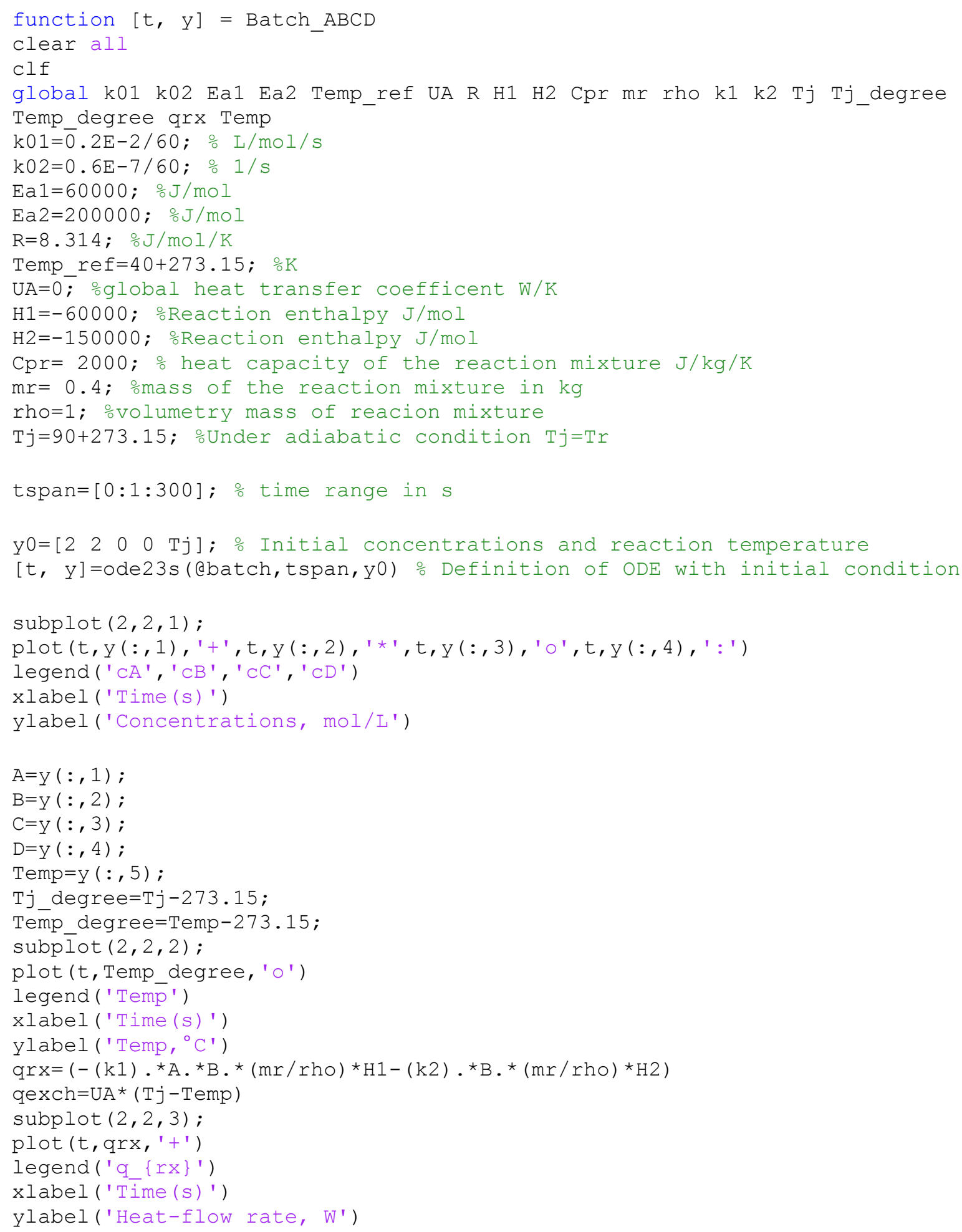


function dydt=batch $(t, y)$

global k01 k02 Ea1 Ea2 Temp_ref mj Cpj Qj UA R H1 H2 Cpr mr rho k1 k2 Tj Tj_degree Temp_degree qrx Témp

$\mathrm{k} 1=\mathrm{k} 01 * \exp (-(\operatorname{Ea} 1 / \mathrm{R}) *((1 / \mathrm{y}(5))-(1 /$ Temp_ref $))) ;$ oModified arrhenius equation $\mathrm{k} 2=\mathrm{k} 02 * \exp (-(\operatorname{Ea} 2 / \mathrm{R}) *((1 / \mathrm{y}(5))-(1 /$ Temp_ref $))) ;$ oModified arrhenius equation $\mathrm{R} 1=\mathrm{k} 1{ }^{*} \mathrm{Y}(1){ }^{*} \mathrm{Y}(2)$;

$\mathrm{R} 2=\mathrm{k} 2 * \mathrm{Y}(2) ;$

$\mathrm{dydt}=\left[-\mathrm{R} 1 ;-\mathrm{R} 1-\mathrm{R} 2 ; \quad+\mathrm{R} 1 ;+\mathrm{R} 2 ; \quad\left(\left(-\mathrm{R} 1\right.\right.\right.$ * $\left.\left.\left.(\mathrm{mr} / \mathrm{rho}){ }^{*} \mathrm{H} 1-\mathrm{R} 2 *(\mathrm{mr} / \mathrm{rho}) * \mathrm{H} 2\right)\right) /(\mathrm{mr} * \mathrm{Cpr})\right]$; \%owatch out: the order of the different ODE should coincide with intial

condition

\section{XXXXXXXXXXXXXXXXXXXXXXXXXXXXXXXXXXXXXXXXXXXXXXXXXXXXXXXXXXXXXX}

The instructor should explain why we used ode23s based on Rosenbrock method. Even better, he should let the students using ode45 and explain the difference of span.

In the code, the other important aspect is in the section function dydt=batch $(t, y)$, to take into account the variation of rate constant with temperature, thus the modified Arrhenius equation should be written as

$\mathrm{k} 1=\mathrm{k} 01 * \exp (-(\operatorname{Ea} 1 / \mathrm{R}) *((1 / \mathbf{y}(\mathbf{5}))-(1 /$ Temp_ref $))) ;$ oModified arrhenius equation $\mathrm{k} 2=\mathrm{k} 02 * \exp (-(\operatorname{Ea} 2 / \mathrm{R}) *((1 / \underline{\underline{\mathbf{y}(5)}})-(1 /$ Temp_ref $))) ;$ oModified arrhenius equation 


\section{Under isoperibolic mode}

\section{The code is}

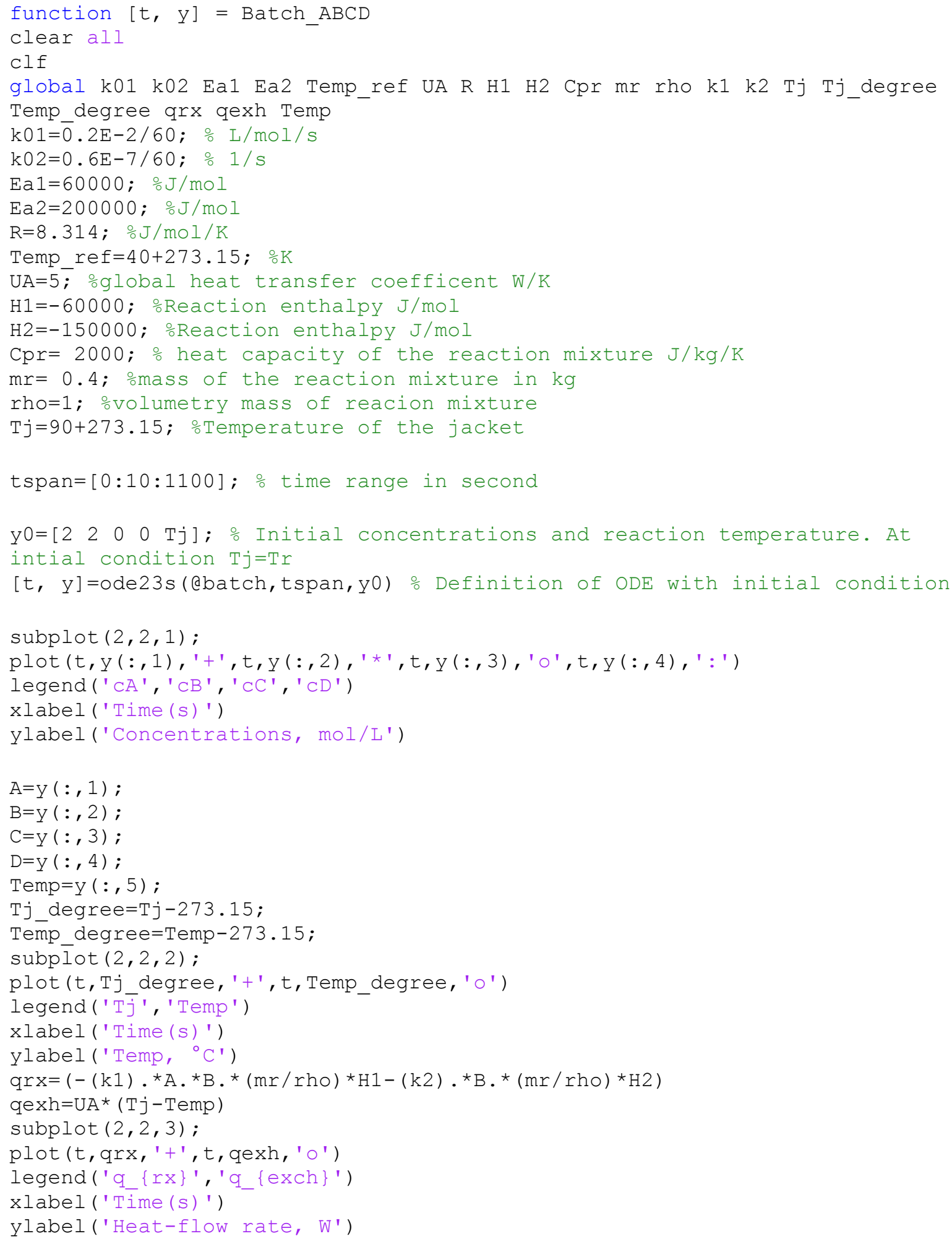


function dydt=batch $(t, y)$

global k01 k02 Eal Ea2 Temp_ref UA R H1 H2 Cpr mr rho k1 k2 Tj Tj_degree

Temp_degree qrx qexh Temp o s'il ya plus de réactions alors vous en écrivez plus

$\mathrm{k} 1=\mathrm{k} 01 * \exp (-(\operatorname{Ea} 1 / \mathrm{R}) *((1 / \mathrm{y}(5))-(1 /$ Temp_ref $))) ;$ oModified Arrhenius equation $\mathrm{k} 2=\mathrm{k} 02 * \exp (-(\mathrm{Ea} 2 / \mathrm{R}) *((1 / \mathrm{y}(5))-(1 /$ Temp_ref $)))$; oModified Arrhenius equation $\mathrm{R} 1=\mathrm{k} 1{ }^{*} \mathrm{Y}(1){ }^{*} \mathrm{Y}(2)$;

$\mathrm{R} 2=\mathrm{k} 2 * \mathrm{Y}(2) ;$

dydt $=[-\mathrm{R} 1 ;-\mathrm{R} 1-\mathrm{R} 2 ;+\mathrm{R} 1 ; \quad+\mathrm{R} 2 ; \quad((-\mathrm{R} 1 *(\mathrm{mr} / \mathrm{rho}) * \mathrm{H} 1-\mathrm{R} 2 *(\mathrm{mr} / \mathrm{rho}) * \mathrm{H} 2)+\mathrm{UA}$ * $(\mathrm{Tj}-$ $\mathrm{Y}(5))) /(\mathrm{mr} * \mathrm{Cpr})]$; oWatch out: the order of the different ODE should coincide with intial condition 
S4: Solutions to project.

Response to question 1.

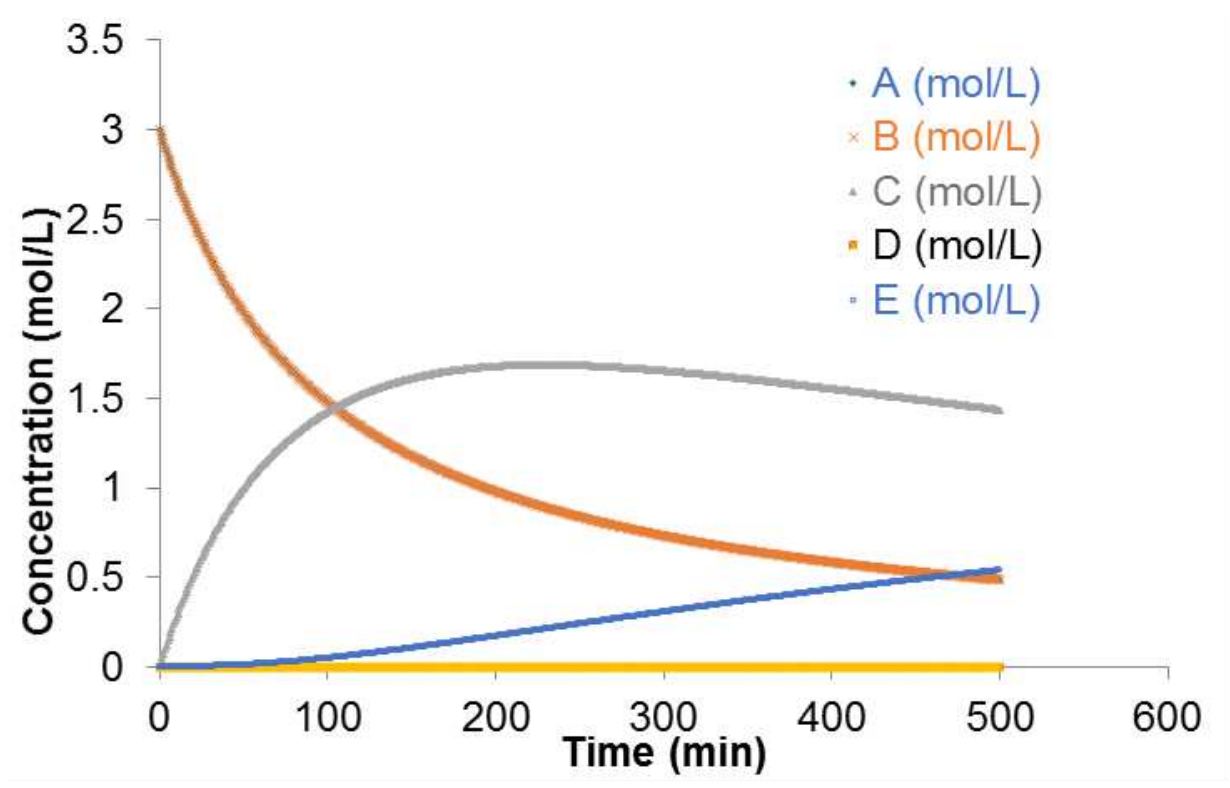

Figure 1. Experiment under isothermal conditions at $130^{\circ} \mathrm{C}$.

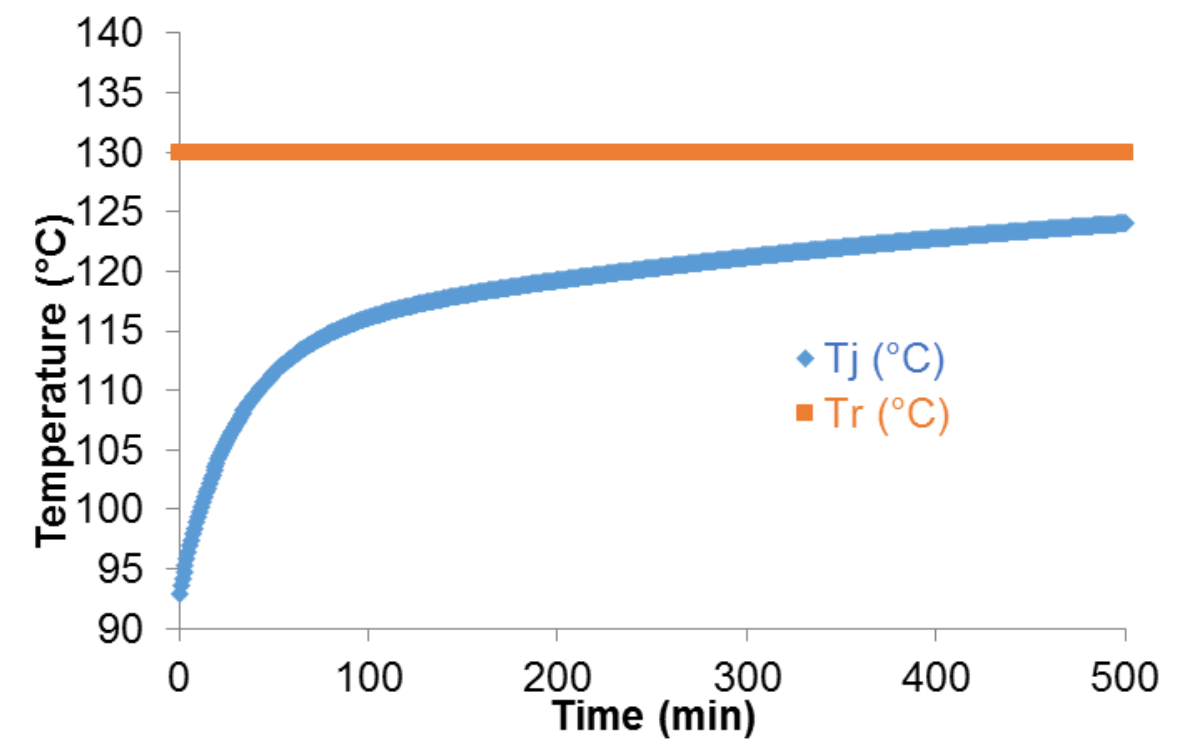

Figure 2. Evolution of $\mathrm{Tj}$ and $\mathrm{Tr}$ under isothermal conditions at $130^{\circ} \mathrm{C}$. 
Response to question 2

Worst case scenario: full adiabatic operation

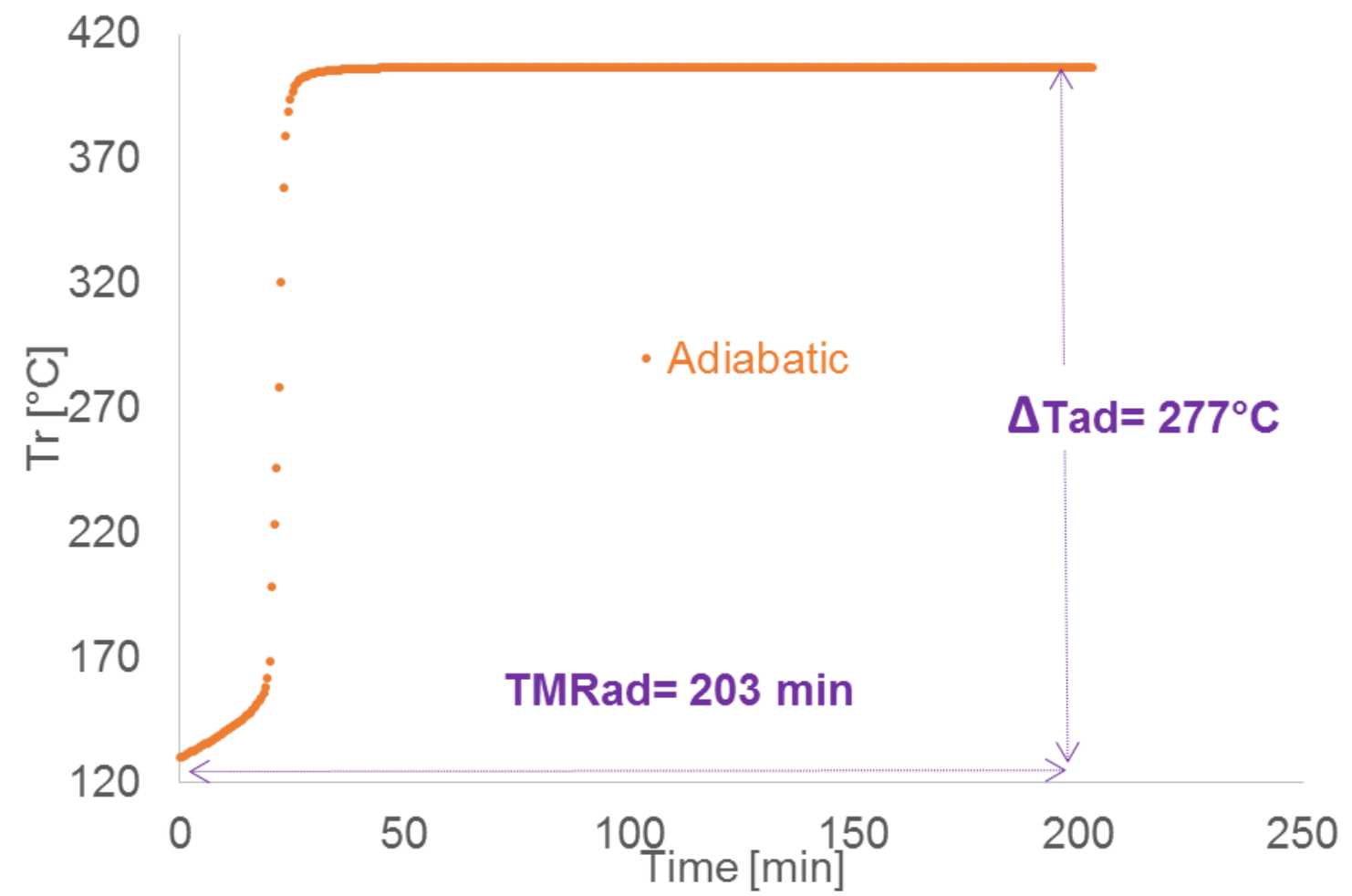

Figure 3. Safety criteria under adiabatic conditions. 
Response to question 3.

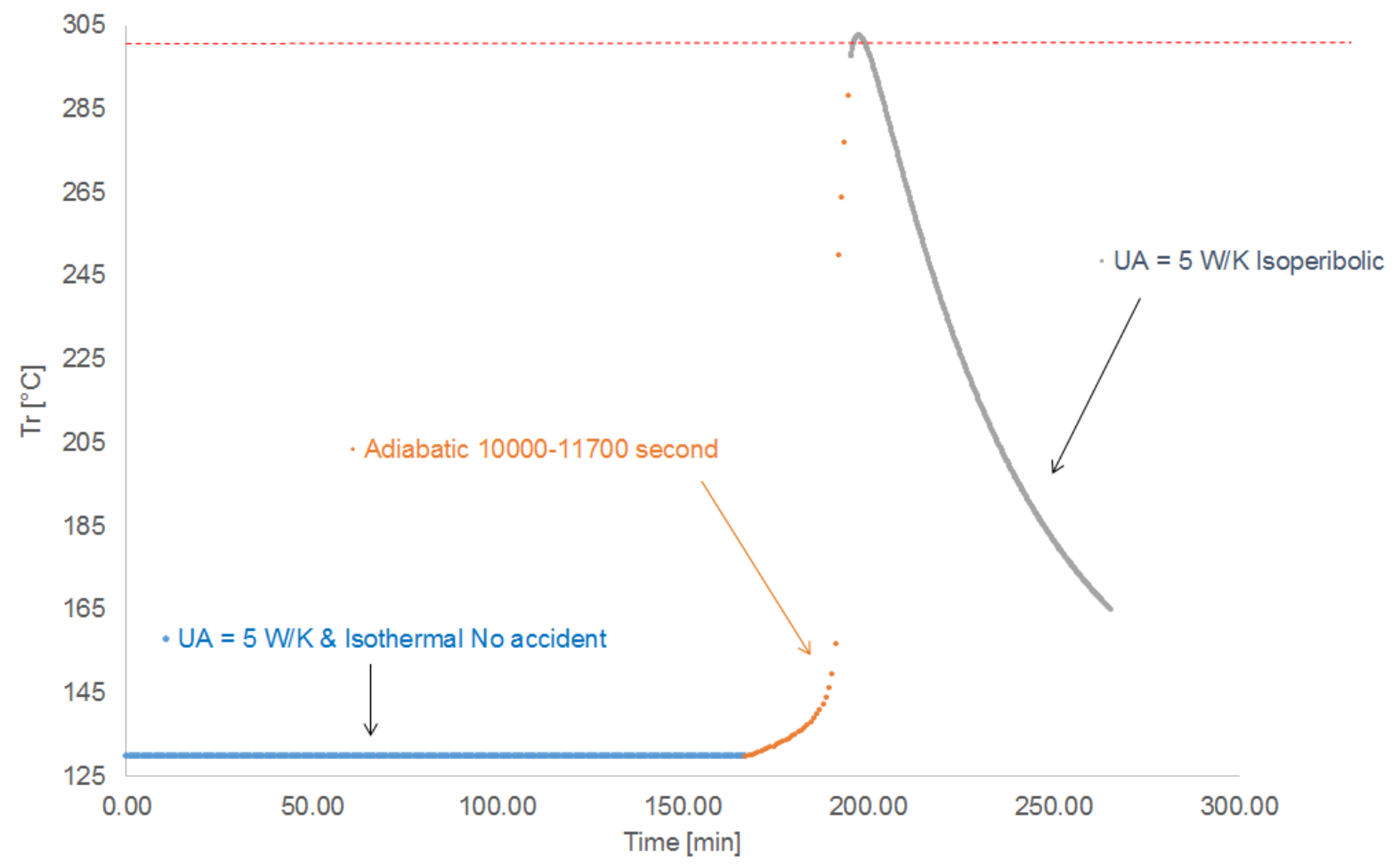

Figure 4. Evolution of reaction temperature when the system moves to adiabatic conditions during the period 10000-11700 seconds. 
Response to question 4

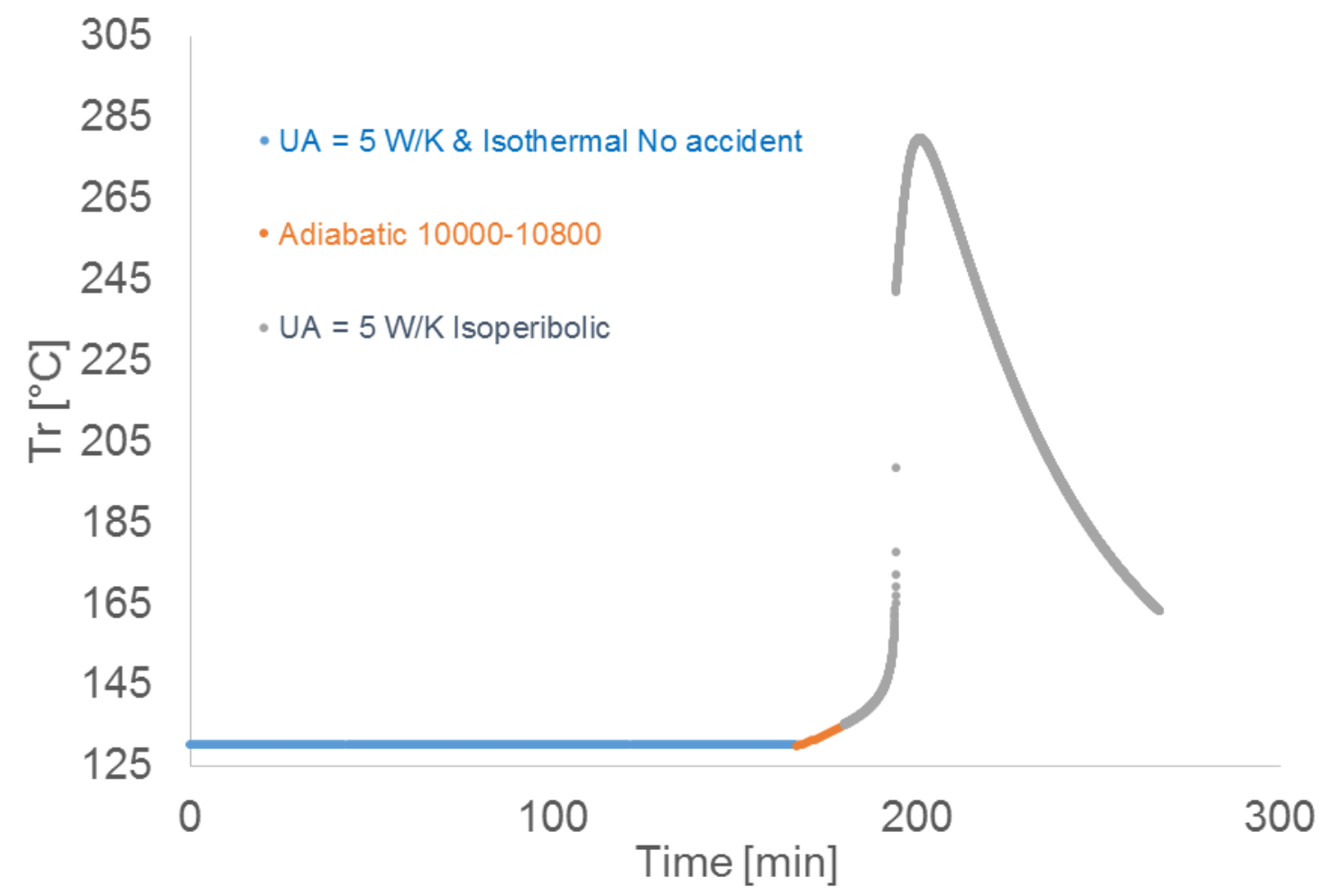

Figure 5. Influence of the adiabatic period on the reaction temperature.

Figure 5 shows that if the adiabatic period last for 800 seconds, then it is possible to avoid the explosion. Hence, time of no return is higher than 800 seconds after a cooling failure at 10000 seconds. 
Response to question 5

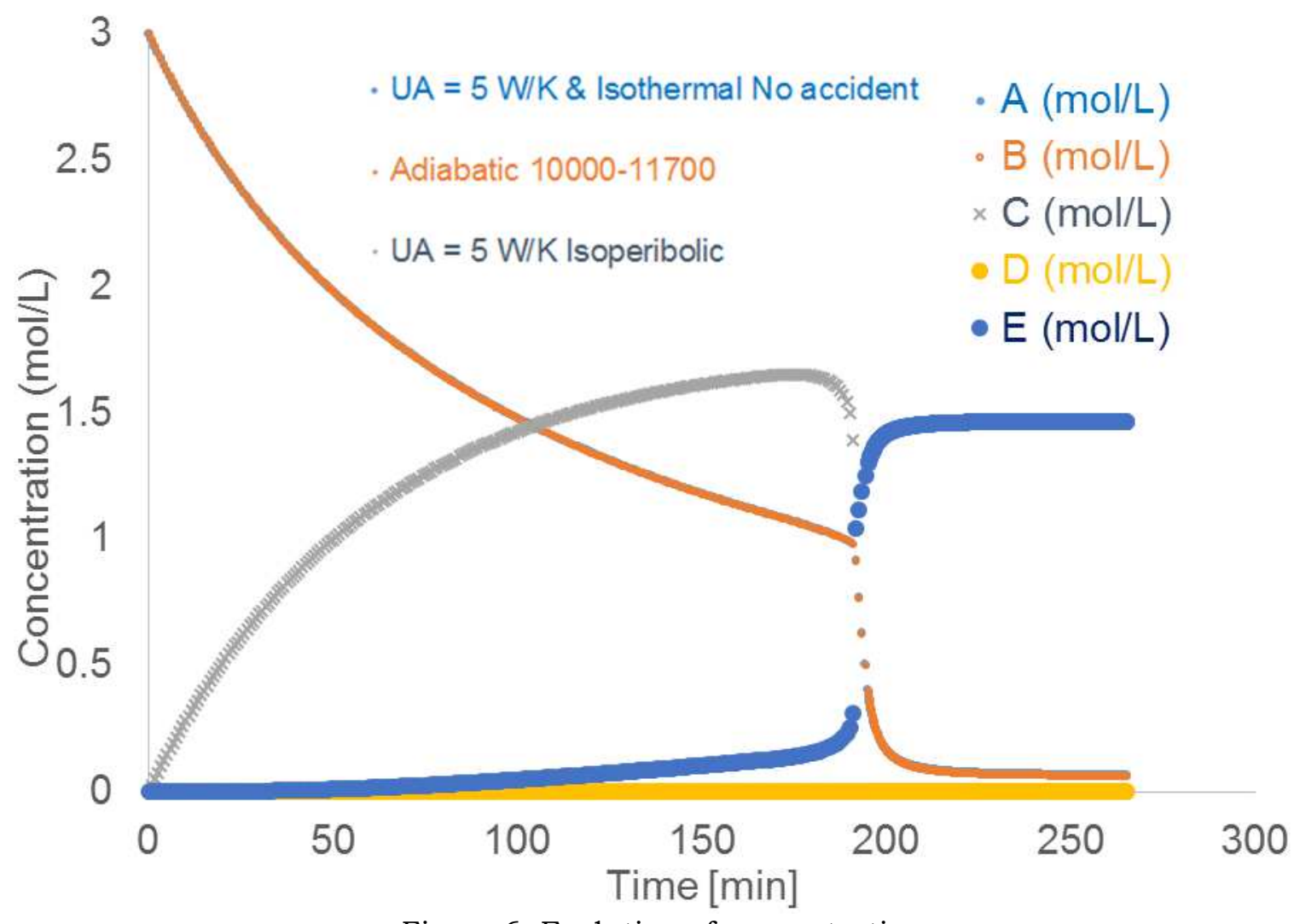

Figure 6. Evolution of concentrations. 


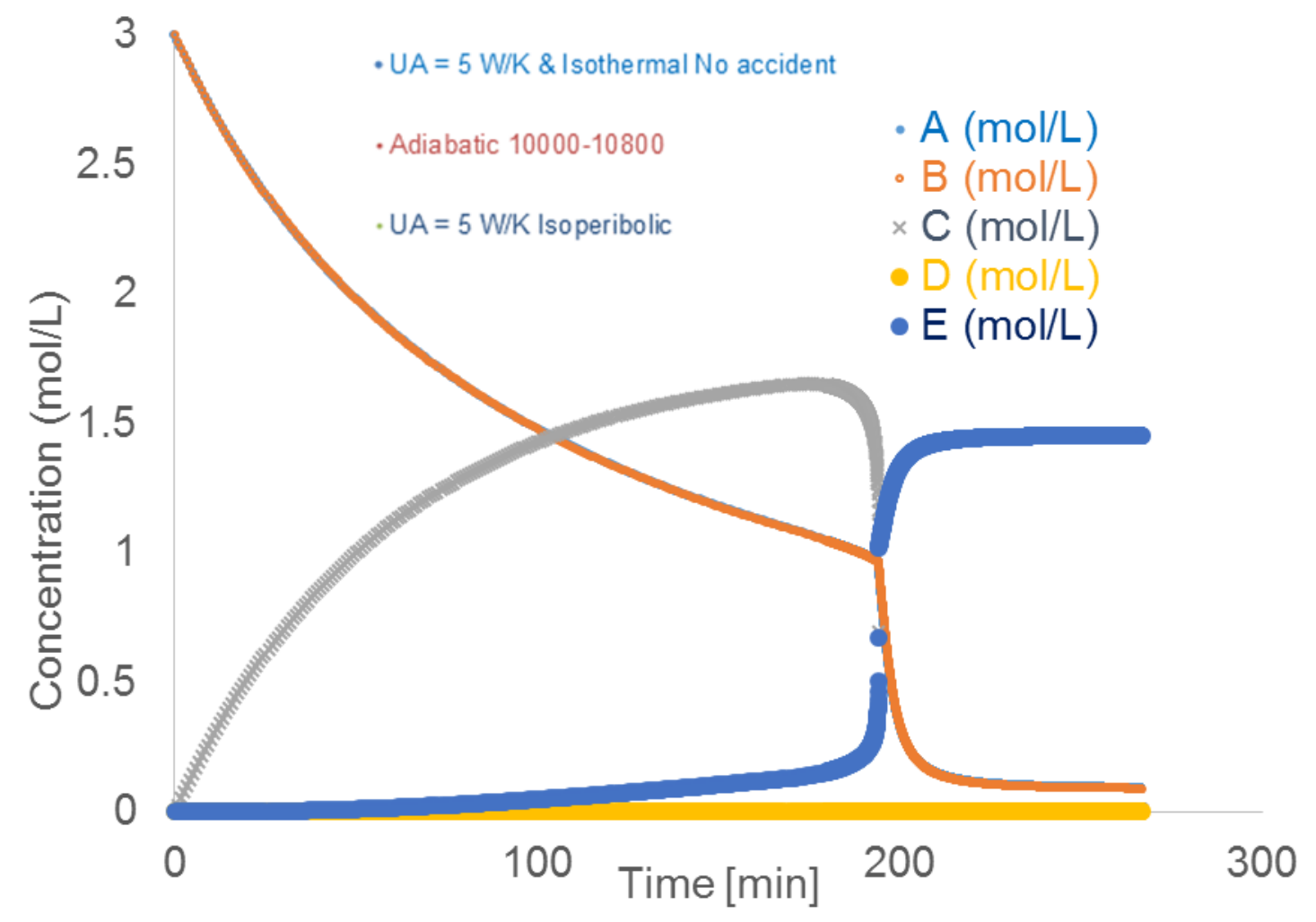

Figure 7. Evolution of concentrations.

Figs. 6 and 7 show that there is a difference of concentration distribution compared to isothermal mode (Figure 1). 